\title{
Azatricyclic Inverse Agonists of ROR $\gamma$ t that Demonstrate Efficacy in Models of Rheumatoid Arthritis and Psoriasis
}

Qingjie Liu, ${ }^{* \dagger}$ Hai-Yun Xiao, ${ }^{\dagger}$ Douglas G. Batt, ${ }^{*}{ }^{\dagger}$ Zili Xiao, ${ }^{\dagger}$ Yeheng Zhu, ${ }^{\dagger}$ Michael G. Yang, ${ }^{\dagger}$ Ning Li,${ }^{\dagger}$ Shiuhang Yip, ${ }^{\dagger}$ Peng Li,${ }^{\dagger}$ Dawn Sun, ${ }^{\dagger}$ Dauh-Rurng Wu, ${ }^{\dagger}$ Max Ruzanov, ${ }^{\dagger}$ John S. Sack, ${ }^{\dagger}$ Carolyn A. Weigelt,${ }^{\dagger}$ Jinhong Wang, ${ }^{\dagger}$ Sha Li,${ }^{\dagger}$ David J. Shuster ${ }^{\dagger}$ Jenny H. Xie, ${ }^{\dagger}$ Y unling Song, ${ }^{\dagger}$ Tara Sherry, ${ }^{\dagger}$ Mary T. Obermeier, ${ }^{\dagger}$ Aberra Fura, ${ }^{\dagger}$ Kevin Stefanski, ${ }^{\dagger}$ Georgia Cornelius, ${ }^{\dagger}$ Silvi Chacko ${ }^{\dagger}$ Purnima Khandelwal, ${ }^{\dagger}$ Shailesh Dudhgaonkar, ${ }^{\star}$ Anjuman Rudra, ${ }^{\star}$ Jignesh Nagar, ${ }^{\star}$ Venkata Murali, ${ }^{\ddagger}$ Arun Govindarajan, ${ }^{\ddagger}$ Rex Denton, ${ }^{\dagger}$ Qihong Zhao, ${ }^{\dagger}$ Nicholas A. Meanwell, ${ }^{\dagger}$ Robert Borzilleri ${ }^{\dagger}$ and T. G. Murali Dhar ${ }^{\dagger}$

†Bristol-Myers Squibb Company, Research and Development, Princeton, New Jersey 085404000, United States

Biocon Bristol-Myers Squibb Research Centre, Biocon Park, Bommasandra IV Phase, Jigani Link Road, Bengaluru 560099, India

*Address correspondence to qingjie.liu@bms.com

\section{SUPPORTING INFORMATION}

Biology Experimental Procedures

page $\mathrm{S} 2$

General

Pharmacokinetic Dosing Vehicles

Mouse Acanthosis Model

Mouse Collagen-Induced Arthritis Model

Chemistry Experimental Procedures

General

page $\mathrm{S} 4$

Synthesis of Compounds 8a-e

page $\mathrm{S} 6$

Synthesis of Compounds 5a-b

page $\mathrm{S} 15$

Synthesis of Compounds $\mathbf{6 a - b}$

page S18

Synthesis of Compounds 7a-b

page $\mathbf{S} 20$

Synthesis of Compounds 3d-e

page $\mathrm{S} 23$

Analytical HPLC trace, ${ }^{1} \mathrm{H}$ NMR, and ${ }^{13} \mathrm{C}$ NMR of $8 \mathbf{e}$

page $\mathrm{S} 25$

Crystallographic parameters for the co-crystal structure of $\mathbf{8 e}$

page $\mathrm{S} 28$

References

page $\mathrm{S} 29$ 


\section{BIOLOGY Experimental Procedures}

All experiments involving animals were performed in accordance with institutional guidelines as defined by the Institutional Animal Care and Use Committee for U. S. institutions. All final compounds were tested in three different ROR isoform GAL4 luciferase-based assays which showed selectivity for the compounds discussed, supporting the belief that this series of compounds does not have a PAINS liability. Protocols for the ROR $\gamma t$ Gal4 Luc Reporter Gene Assay, ROR $\gamma \mathrm{t}$ hWB IL17 Assay and ROR $\gamma \mathrm{t}$ mWB IL17 Assay have been previously described. ${ }^{1}$

Abbreviations: NMP, N-methylpyrrolidinone; TPGS, tocopheryl polyethylene glycol succinate.

\section{Pharmacokinetic Study Dosing Vehicles}

Rodent IV: 67.5\% PEG 400, 25.5\% water, 4.5\% Pluronic F-68, 2.5\% NMP

Dog, cyno IV: $70 \%$ PEG 400, 30\% water

PO: $55 \%$ PEG 400, 20\% propylene glycol, 20\% TPGS, 5\% ethanol

\section{Mouse Acanthosis Model}

To induce acanthosis, recombinant dual chain human IL-23 (produced at BMS) was diluted in sterile phosphate buffered saline and injected ( $5 \mu \mathrm{g}$ in $20 \mu \mathrm{L})$ into the right ear of C57bl/6 female mice, every other day until the last injection on day 10 . Each ear was injected intradermally using an ultra-fine $0.5 \mathrm{cc}$ insulin syringe (BD Ultra-fine II \#32846 needle, 31 gauge, 5/16 inch length). Starting baseline measurements of the uninjected right ear of each mouse was made on day 0 . Thereafter, ear thickness (in thousandths of an inch) was measured every other day, prior to the next ear injection, using a Mitutoyo (\#2412F) dial caliper. Oral dosing with compound 8e began approximately $2 \mathrm{~h}$ before the first IL-23 injection and continued BID until day 10, and the study ended on day 11. Compound 8e was formulated as a solution in NMP:TPGS:PEG 300 $(5: 19: 76)$ vehicle. The placebo/control group was dosed with blank vehicle. The recombinant dual chain human anti-IL-23 was administered SC at doses of $3 \mathrm{mg} / \mathrm{kg}$ on Day $0,3,7$ and 10 and was used as the positive control. The results are expressed as mean, standard deviation and/or standard error of the mean (SEM) for each group. Data calculations were performed in Excel (Microsoft, Redmond, WA), while statistical analysis (ANOVA with Dunnett's posttest) and graphics were done using GraphPad Prism software (GraphPad, San Diego, CA). For histology, the resected right ears were fixed in 10\% formalin for $24 \mathrm{~h}$. Each ear was longitudinally cut in half, the cut edges were embedded face down in one paraffin block. The blocks were sectioned at $5 \mu \mathrm{m}$ and H\&E staining was performed on the sections. A composite histological score to evaluate levels of acanthosis and inflammatory damage separately was developed, range from 0 to 4 (0: normal; 1 ; minimal; 2: mild; 3 : moderate; 4: marked), and applied to evaluate the histologic changes in all slides. The slides were scored blindly by two independent investigators and the mean score was recorded.

\section{Mouse Collagen-Induced Arthritis Model}

Male DBA/1 mice (8-10 weeks of age, Harlan) were randomized into different treatment groups based on body weight and primed with bovine type II collagen (Chondrex \#20021) in adjuvant (Sigma adjuvant system, Sigma Aldrich \#S6322) at the base of the tail on day 1 and on day 21. Animals were dosed with compound $\mathbf{8 e}$ by oral gavage twice daily with 5, 10 and $20 \mathrm{mg} / \mathrm{kg}$ 
(starting day 1) or administered $10 \mathrm{mg} / \mathrm{kg}$ of a murine equivalent of the TNF decoy receptor etanercept (mEnbrel), intraperitonealy, twice weekly. Control animals were dosed with vehicle (55\% PEG 400, 20\% TPGS, 20\% propylene glycol, 5\% EtOH). Disease activity was monitored and scored periodically using standard criteria (0: normal; 1 : mild, but definite redness and swelling of the ankle or wrist, or apparent redness and swelling limited to individual digits regardless of number of affected digits; 2: moderate redness and swelling of ankle or wrist; 3 : severe redness and swelling of the entire paw including digits; 4: maximally inflamed limb with involvement of multiple joints). Prior to termination of the experiment, mice were bled at various time points ( $1 \mathrm{~h}, 4 \mathrm{~h}, 7 \mathrm{~h}, 8 \mathrm{~h}, 24 \mathrm{~h})$ post dose to capture the complete pharmacokinetic profile of the compound. Plasma IL-6 was measured by commercial ELISA Kit (BD Biosciences \#555240) and anti-collagen II antibody levels were determined by in-house developed ELISA. At the end of the experiment, paws were collected for histology. Paws were fixed, decalcified and embedded in paraffin. Sections were cut in the sagittal plane, stained with H\&E and evaluated microscopically. Lesions were scored blindly on a severity scale of 0 (normal) to 4 in two separate categories: inflammation (cellular infiltration, pannus formation and edema) and bone resorption. For inflammation/edema, the scoring was as follows: Grade 0, unremarkable; grade 1, minimal change; grade 2, mild change; grade 3, moderate change; grade 4, marked change. For bone resorption, the grading was as follows: Grade 0 , unremarkable; grade 1, minimal focal to multifocal cortical or trabecular bone resorption; grade 2 , mild focal to multifocal cortical or trabecular bone resorption; grade 3, moderate resorption of cortical or trabecular bone with rare full-thickness resorption; grade 4, full-thickness resorption with distortion of bone architecture. Scores for each group were compared by one-way analysis of variance and Dunnett's multiple comparison test. 


\section{CHEMISTRY Experimental Procedures}

All commercially available chemicals and solvents were used without further purification. Reactions were generally performed under an atmosphere of nitrogen or argon. Column chromatography was performed using pre-packed silica gel cartridges on a CombiFlash instrument (Teledyne ISCO). All new intermediates and compounds gave satisfactory ${ }^{1} \mathrm{H}$ and/or LCMS results. ${ }^{1} \mathrm{H}$ NMR spectra were obtained on a Bruker $400 \mathrm{MHz}$ or a JEOL $500 \mathrm{MHz}$ NMR spectrometer using TMS as an internal reference. Electrospray ionization (ESI) mass spectra were obtained on a Waters ZQ single quadrupole mass spectrometer. The purities of final tested compounds was determined by analytical HPLC via UV detection at $220 \mathrm{~nm}$. HPLC methods are shown below:

Method A: Column: Acquity UPLC BEH C 182.1 x 50 mm, $1.7 \mu \mathrm{m}$ (Waters Corp.); mobile phase A: water with $0.05 \%$ TFA; mobile phase $\mathrm{B}$ : $\mathrm{MeCN}$ with $0.05 \% \mathrm{TFA}$; temp: $50{ }^{\circ} \mathrm{C}$; flow rate 0.80 $\mathrm{mL} / \mathrm{min}$; gradient: $2-98 \% \mathrm{~B}$ over $1 \mathrm{~min}$, then $0.5 \mathrm{~min}$ isocratic at $98 \% \mathrm{~B}$.

Method B: Column: XBridge $\mathrm{C}_{18} 2.1$ x $50 \mathrm{~mm}, 1.7 \mu \mathrm{m}$ (Waters Corp.); mobile phase A: MeCNwater 5:95 with $0.1 \%$ TFA; mobile phase $\mathrm{B}$ : 95:5 MeCN-water with $0.1 \%$ TFA; temp: $50{ }^{\circ} \mathrm{C}$; flow rate $1 \mathrm{~mL} / \mathrm{min}$; gradient: $0-100 \% \mathrm{~B}$ over $3 \mathrm{~min}$, then isocratic at $100 \% \mathrm{~B}$.

Method C: Column: XBridge $\mathrm{C}_{18} 2.1$ x $50 \mathrm{~mm}, 1.7 \mu \mathrm{m}$ (Waters Corp.); mobile phase A: MeCNwater 5:95 with $10 \mathrm{mM}$ ammonium acetate; mobile phase B: 95:5 MeCN-water with $10 \mathrm{mM}$ ammonium acetate; temp: $50{ }^{\circ} \mathrm{C}$; flow rate $1 \mathrm{~mL} / \mathrm{min}$; gradient: $0-100 \% \mathrm{~B}$ over $3 \mathrm{~min}$, then isocratic at $100 \% \mathrm{~B}$.

Method D: Column: ACE UCore SuperC ${ }_{18} 3$ x 125 mm, $2.5 \mu \mathrm{m}$ (Waters Corp.); mobile phase A: MeCN-water 5:95 with 0.05\% TFA; mobile phase B: 95:5 MeCN-water with 0.05\% TFA; temp: $\mathrm{rt}$; flow rate $1 \mathrm{~mL} / \mathrm{min}$; gradient: $10-100 \% \mathrm{~B}$ over $12 \mathrm{~min}$, then isocratic at $100 \% \mathrm{~B}$.

Method E: Column: ACE UCore SuperHexPh 3 x 125 mm, $2.5 \mu \mathrm{m}$ (Waters Corp.); mobile phase A: MeCN-water 5:95 with 0.05\% TFA; mobile phase B: 95:5 MeCN-water with 0.05\% TFA; temp: rt; flow rate $1 \mathrm{~mL} / \mathrm{min}$; gradient: $10-100 \% \mathrm{~B}$ over $12 \mathrm{~min}$, then isocratic at $100 \% \mathrm{~B}$.

Method F: Column: Sunfire $\mathrm{C}_{18} 3$ x $150 \mathrm{~mm}, 3.5 \mu \mathrm{m}$ (Waters Corp.); mobile phase A: MeCNwater 5:95 with 0.05\% TFA; mobile phase B: 95:5 MeCN-water with 0.05\% TFA; temp: rt; flow rate $1 \mathrm{~mL} / \mathrm{min}$; gradient: $10-100 \% \mathrm{~B}$ over $12 \mathrm{~min}$, then isocratic at $100 \% \mathrm{~B}$.

Method G: Column: XBridge phenyl 3 x $150 \mathrm{~mm}, 3.5 \mu \mathrm{m}$ (Waters Corp.); mobile phase A: MeCN-water 5:95 with 0.05\% TFA; mobile phase B: 95:5 MeCN-water with 0.05\% TFA; temp: rt; flow rate $1 \mathrm{~mL} / \mathrm{min}$; gradient: $10-100 \% \mathrm{~B}$ over $12 \mathrm{~min}$, then isocratic at $100 \% \mathrm{~B}$.

Method H (preparative): Column: XBridge $\mathrm{C}_{18} 19$ x $200 \mathrm{~mm}, 5 \mu \mathrm{m}$ (Waters Corp.); mobile phase A: 5:95 MeCN-water with 0.1\% TFA; mobile phase B: 95:5 MeCN-water with 0.1\% TFA; flow rate $20 \mathrm{~mL} / \mathrm{min}$; gradient: increasing $\mathrm{B}$, then isocratic at $100 \% \mathrm{~B}$.

Method J (preparative): Column: XBridge $\mathrm{C}_{18} 19 \times 200 \mathrm{~mm}, 5 \mu \mathrm{m}$ (Waters Corp.); mobile phase A: 5:95 MeCN-water with $10 \mathrm{mM}$ ammonium acetate; mobile phase B: 95:5 MeCN-water with $10 \mathrm{mM}$ ammonium acetate; flow rate $20 \mathrm{~mL} / \mathrm{min}$; gradient: increasing $\mathrm{B}$, then isocratic at $100 \%$ B. 
Method K (preparative): Column: Luna $\mathrm{C}_{18} 30$ x $100 \mathrm{~mm}, 5 \mu \mathrm{m}$ (Phenomenex Inc.); mobile phase A: water with $0.1 \%$ TFA; mobile phase $\mathrm{B}$ : $\mathrm{MeCN}$ with $0.1 \% \mathrm{TFA}$; flow rate $30 \mathrm{~mL} / \mathrm{min}$; gradient: increasing $\mathrm{B}$, then isocratic at $100 \% \mathrm{~B}$.

Abbreviations: HATU, hexafluorophosphate azabenzotriazole tetramethyl uronium; mCPBA, m-chloroperoxybenzoic acid. 
Scheme S1. Synthesis of Compounds 8a-e
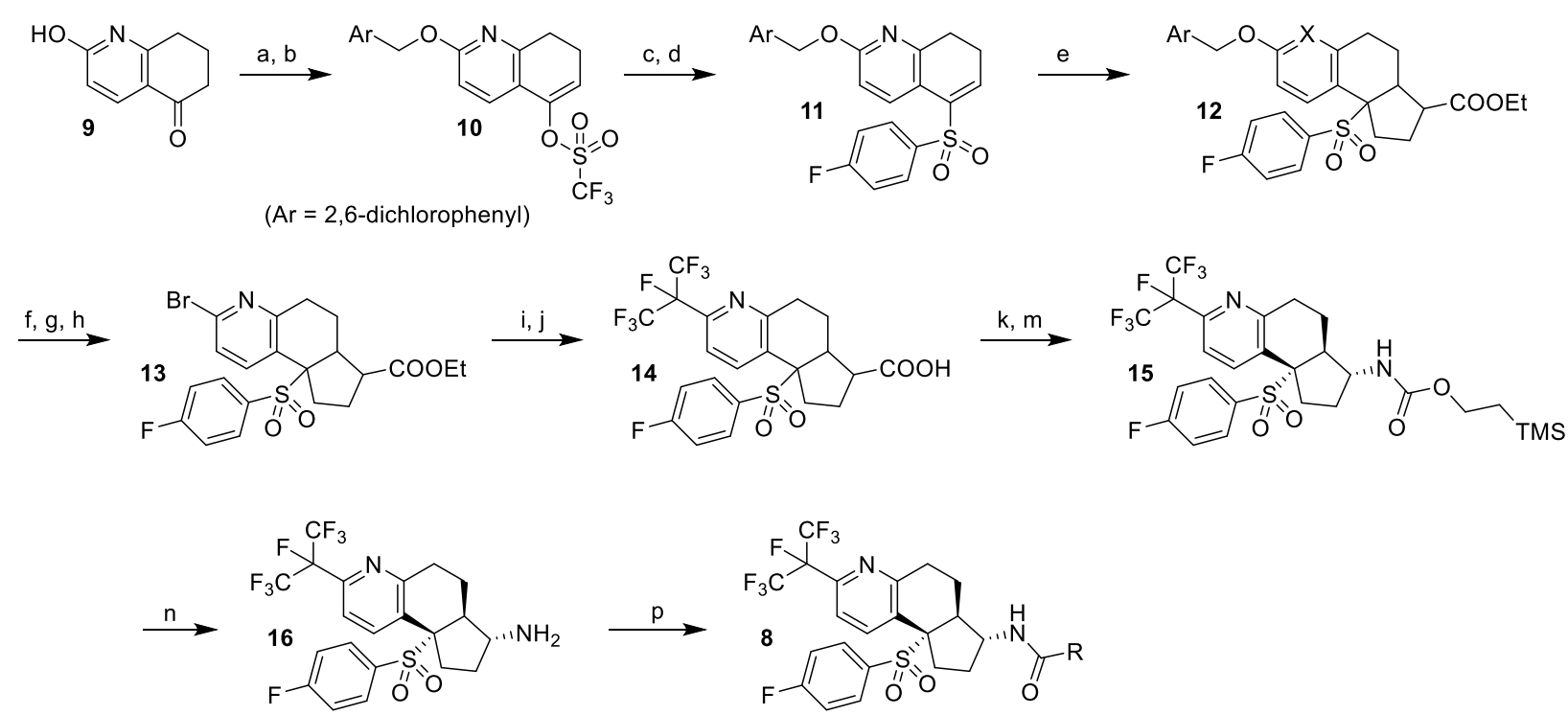

Reagents and conditions: (a) 2,6-dichlorobenzyl bromide, $\mathrm{Cs}_{2} \mathrm{CO}_{3}, \mathrm{MeCN}, \mathrm{rt}, 85 \%$; (b) $\left(\mathrm{CF}_{3} \mathrm{SO}_{2}\right)_{2} \mathrm{NPh}$, KHMDS, $-78^{\circ} \mathrm{C}$, $99 \%$; (c) 4-fluorobenzenethiol, $\mathrm{Pd}_{2}(\mathrm{dba})_{3}$, xantphos, $i$-PrNEt 2 , dioxane, $120^{\circ} \mathrm{C}$; (d) mCPBA, DCM, $0{ }^{\circ} \mathrm{C}$ to rt, 79-89\% (2 steps); (e) ethyl 4-chlorobutanoate, LiHMDS, THF, $-78^{\circ} \mathrm{C}, 64 \%$; (f) $\mathrm{HCl}$, dioxane, DCE, $50{ }^{\circ} \mathrm{C}, 18 \mathrm{~h}$; (g) $\left(\mathrm{CF}_{3} \mathrm{SO}_{2}\right) \mathrm{O}$, pyridine, DCM; (h) LiBr, TsOH, DCM, $50{ }^{\circ} \mathrm{C}, 16 \mathrm{~h}, 72 \%$ (3 steps); (i) activated $\mathrm{Cu}, \mathrm{IC}\left(\mathrm{CF}_{3}\right)_{2} \mathrm{~F}, \mathrm{DMF}, 120$ ${ }^{\circ} \mathrm{C}, \sim 100 \%$; (j) LiOH, THF-EtOH- $\mathrm{H}_{2} \mathrm{O}$, rt, $\sim 100 \%$; (k) DPPA, Et $3 \mathrm{~N}$, toluene, $0{ }^{\circ} \mathrm{C}$ to rt; 2 (trimethylsilyl)ethan-1-ol, $80^{\circ} \mathrm{C}, 90 \mathrm{~min}, 98 \%$; (m) SFC, (R,R)Whelk-O1 column, 31\%; (n) $\mathrm{HCl}$, dioxane, DCE, $50{ }^{\circ} \mathrm{C}, 3 \mathrm{~h}, 99 \%$. (p) RCOOH, HATU, $i-\mathrm{PrNEt}_{2}$, DMF, rt, 53-72\%.

\section{2-Hydroxy-7,8-dihydroquinolin-5(6H)-one (9).}

A mixture of 3-amino-2-cyclohexen-1-one ( $12.0 \mathrm{~g}, 108 \mathrm{mmol})$ and ethyl propiolate (14.6 $\mathrm{mL}, 144 \mathrm{mmol}$ ) was heated to $100{ }^{\circ} \mathrm{C}$. Slow gas evolution was observed, lasting a few minutes. After heating at $100{ }^{\circ} \mathrm{C}$ overnight, the temperature was increased to $170{ }^{\circ} \mathrm{C}$ for $2 \mathrm{~h}$. The mixture was cooled to about $70^{\circ} \mathrm{C}$, and treated dropwise over 20 min with $\mathrm{MeOH}(35 \mathrm{~mL})$. The resulting suspension was stirred at $70^{\circ} \mathrm{C}$ for $2 \mathrm{~h}$, then was cooled to $0{ }^{\circ} \mathrm{C}$ and stirred for $1 \mathrm{~h}$. The precipitate was collected by filtration, washed with DCM-heptane $(1: 2,30 \mathrm{~mL})$ and $\mathrm{MeOH}(10$ $\mathrm{mL}$ ) and dried to provide 9 as a yellow-brown solid (4.40 g, 25\% yield.) HPLC $t_{\mathrm{R}} 0.46 \mathrm{~min}$ (method A). LCMS $m / z$ calcd for $\mathrm{C}_{9} \mathrm{H}_{10} \mathrm{NO}_{2}[\mathrm{M}+\mathrm{H}]^{+}$164.1, obsd 163.9. ${ }^{1} \mathrm{H}$ NMR $(499 \mathrm{MHz}$, DMSO-d 6 ) $\delta 12.08(\mathrm{br} \mathrm{s}, 1 \mathrm{H}), 7.77(\mathrm{~d}, \mathrm{~J}=9.5 \mathrm{~Hz}, 1 \mathrm{H}), 6.24(\mathrm{~d}, \mathrm{~J}=9.5 \mathrm{~Hz}, 1 \mathrm{H}), 2.79$ (t, J=6.2 Hz, $2 \mathrm{H}$ ), $2.44-2.40(\mathrm{~m}, 2 \mathrm{H}), 2.00$ (quin, $\mathrm{J}=6.4 \mathrm{~Hz}, 2 \mathrm{H}$ ).

\section{2-((2,6-Dichlorobenzyl)oxy)-7,8-dihydroquinolin-5-yl trifluoromethanesulfonate (10).}

A mixture of 9 (8.65 g, $53.0 \mathrm{mmol})$, 2-(bromomethyl)-1,3-dichlorobenzene (15.3 g, 63.6 $\mathrm{mmol})$, and $\mathrm{Cs}_{2} \mathrm{CO}_{3}(17.3 \mathrm{~g}, 53.0 \mathrm{mmol})$ in $\mathrm{MeCN}(200 \mathrm{~mL})$ was stirred at $\mathrm{rt}$ for $22 \mathrm{~h}$. The mixture was filtered and the filtrates were concentrated. The residue was partitioned between 
EtOAc and water. The organic phase was washed with brine, dried over $\mathrm{MgSO}_{4}$, and concentrated. The residue was purified by column chromatography on silica gel $(220 \mathrm{~g})$, eluting with EtOAc-hexanes (gradient from 5-10\%) to provide 2-((2,6-dichlorobenzyl)oxy)-7,8dihydroquinolin-5(6H)-one as a white solid (14.5 g, 85\% yield). HPLC $t_{\mathrm{R}} 1.11 \mathrm{~min}(\operatorname{method} \mathrm{A})$. LCMS $m / z$, calcd for $\mathrm{C}_{16} \mathrm{H}_{14} \mathrm{Cl}_{2} \mathrm{NO}_{2}[\mathrm{M}+\mathrm{H}]^{+}$322.0, 324.0; obsd 322.0, 323.9. ${ }^{1} \mathrm{H} \mathrm{NMR}$ (499 $\left.\mathrm{MHz} \mathrm{CDCl}_{3}\right) \delta 8.19(\mathrm{~d}, \mathrm{~J}=8.6 \mathrm{~Hz}, 1 \mathrm{H}), 7.39-7.36(\mathrm{~m}, 2 \mathrm{H}), 7.28-7.24(\mathrm{~m}, 1 \mathrm{H}), 6.69(\mathrm{~d}, \mathrm{~J}=8.6$ $\mathrm{Hz}, 1 \mathrm{H}), 5.68$ (s, 2H), $3.08(\mathrm{t}, \mathrm{J}=6.2 \mathrm{~Hz}, 2 \mathrm{H}), 2.69-2.60(\mathrm{~m}, 2 \mathrm{H}), 2.19$ (quin, J=6.4 Hz, 2H).

A solution of this material $(8.24 \mathrm{~g}, 25.6 \mathrm{mmol})$ and $N, N$-bis(trifluoromethylsulfonyl)aniline (11.9 g, $33.2 \mathrm{mmol})$ in THF at $-78^{\circ} \mathrm{C}$ was treated with $1 \mathrm{M}$ potassium bis(trimethylsilyl)amide $(34.5 \mathrm{~mL}, 34.5 \mathrm{mmol})$ over $10 \mathrm{~min}$. After $80 \mathrm{~min}$ at $-78^{\circ} \mathrm{C}$, the mixture was treated with water and warmed to rt. Saturated aq $\mathrm{NaHCO}_{3}$ was added and the mixture was extracted with ether. The organic phase was washed with brine, dried over $\mathrm{Na}_{2} \mathrm{SO}_{4}$ and concentrated. The residue was purified by column chromatography on silica gel (220 g), eluting with EtOAchexanes (gradient from 0-5\%) to provide $\mathbf{1 0}$ as a colorless syrup (11.7 g, quantitative yield). HPLC $t_{\mathrm{R}} 1.30 \mathrm{~min}$ (method A). LCMS $\mathrm{m} / z$ calcd for $\mathrm{C}_{17} \mathrm{H}_{13} \mathrm{Cl}_{2} \mathrm{~F}_{3} \mathrm{NO}_{4} \mathrm{~S}[\mathrm{M}+\mathrm{H}]^{+}$454.0, 456.0; obsd 454.1, 455.9. ${ }^{1} \mathrm{H}$ NMR (499 MHz, $\left.\mathrm{CDCl}_{3}\right) \delta 7.54(\mathrm{~d}, \mathrm{~J}=8.5 \mathrm{~Hz}, 1 \mathrm{H}), 7.39(\mathrm{~d}, \mathrm{~J}=8.1 \mathrm{~Hz}$, 2H), $7.27-7.21(\mathrm{~m}, 1 \mathrm{H}), 6.68(\mathrm{~d}, \mathrm{~J}=8.5 \mathrm{~Hz}, 1 \mathrm{H}), 5.94(\mathrm{t}, \mathrm{J}=4.8 \mathrm{~Hz}, 1 \mathrm{H}), 5.62(\mathrm{~s}, 2 \mathrm{H}), 3.04(\mathrm{t}$, $\mathrm{J}=8.6 \mathrm{~Hz}, 2 \mathrm{H}), 2.63(\mathrm{td}, \mathrm{J}=8.6,4.8 \mathrm{~Hz}, 2 \mathrm{H})$.

\section{2-((2,6-Dichlorobenzyl)oxy)-5-((4-fluorophenyl)sulfonyl)-7,8-dihydroquinoline (11).}

A mixture of 10 (20.2 g, $44.5 \mathrm{mmol}$ ), 4,5-bis(diphenylphosphino)-9,9-dimethylxanthene (Xantphos; $1.29 \mathrm{~g}, 2.22 \mathrm{mmol}$ ), tris(dibenzylideneacetone)dipalladium(0) (1.63 g, $1.78 \mathrm{mmol}$ ), and $i$-PrNEt $2(14 \mathrm{~mL}, 80 \mathrm{mmol})$ was dissolved in 1,4-dioxane $(127 \mathrm{~mL})$ in a pressure bottle. 4 Fluorobenzenethiol $(8.5 \mathrm{~mL}, 80 \mathrm{mmol})$ was added. The mixture was bubbled with $\mathrm{N}_{2}$ for $5 \mathrm{~min}$, then sealed under $\mathrm{N}_{2}$ and heated at $115^{\circ} \mathrm{C}$ for $3 \mathrm{~h}$. The mixture was cooled to rt, filtered through a Celite pad, and the solids were washed with ether. The combined filtrates were partitioned between saturated aq $\mathrm{NaHCO}_{3}$ and ether. The organic phase was washed with brine, dried over $\mathrm{MgSO}_{4}$ and concentrated. The residue was purified by column chromatography on silica gel (750 g), eluting with EtOAc-hexanes (gradient from 0-25\%) to provide 2-((2,6-dichlorobenzyl)oxy)5-((4-fluorophenyl)thio)-7,8-dihydroquinoline as a light yellow syrup (16.0 g, 83\% yield). HPLC $t_{\mathrm{R}} 1.36$ min (method A). LCMS $\mathrm{m} / z$ calcd for $\mathrm{C}_{22} \mathrm{H}_{17} \mathrm{Cl}_{2} \mathrm{FNOS}[\mathrm{M}+\mathrm{H}]^{+}$432.0, 434.0; obsd 432.0, 434.0. ${ }^{1} \mathrm{H}$ NMR (499 MHz, $\left.\mathrm{CDCl}_{3}\right) \delta 7.65(\mathrm{~d}, \mathrm{~J}=8.5 \mathrm{~Hz}, 1 \mathrm{H}), 7.36(\mathrm{~d}, \mathrm{~J}=8.0 \mathrm{~Hz}, 2 \mathrm{H}), 7.26-7.21$ $(\mathrm{m}, 3 \mathrm{H}), 6.96(\mathrm{t}, \mathrm{J}=8.7 \mathrm{~Hz}, 2 \mathrm{H}), 6.52(\mathrm{~d}, \mathrm{~J}=8.5 \mathrm{~Hz}, 1 \mathrm{H}), 6.40(\mathrm{t}, \mathrm{J}=4.6 \mathrm{~Hz}, 1 \mathrm{H}), 5.58(\mathrm{~s}, 2 \mathrm{H}), 3.01$ $(\mathrm{t}, \mathrm{J}=8.4 \mathrm{~Hz}, 2 \mathrm{H}), 2.57$ (td, J=8.4, $4.6 \mathrm{~Hz}, 2 \mathrm{H})$.

A solution of this material $(16.0 \mathrm{~g}, 37.0 \mathrm{mmol})$ in $\mathrm{DCM}(460 \mathrm{~mL})$ at $0{ }^{\circ} \mathrm{C}$ was treated portionwise with mCPBA $(19.9 \mathrm{~g}, 89 \mathrm{mmol})$. The suspension was stirred at $0{ }^{\circ} \mathrm{C}$ for $2 \mathrm{~h}$, then was filtered. The collected solid was washed with DCM and the combined filtrates were stirred with saturated aq $\mathrm{NaHCO}_{3}$ for $10 \mathrm{~min}$. The organic phase was separated, washed with saturated aq $\mathrm{NaHCO} 3,10 \%$ aq $\mathrm{Na}_{2} \mathrm{~S}_{2} \mathrm{O}_{3}$ and brine, dried over $\mathrm{MgSO}_{4}$ and concentrated to provide 11 as an off-white solid (16.25 g, 95\% yield). HPLC $t_{\mathrm{R}} 1.19 \mathrm{~min}$ (method A). LCMS $\mathrm{m} / z$ calcd for $\mathrm{C}_{22} \mathrm{H}_{17} \mathrm{Cl}_{2} \mathrm{FNO}_{3} \mathrm{~S}[\mathrm{M}+\mathrm{H}]^{+}$464.0, 466.0; obsd 464.0, 466.0. ${ }^{1} \mathrm{H} \mathrm{NMR}\left(499 \mathrm{MHz}, \mathrm{CDCl}_{3}\right) \delta 8.08$ $(\mathrm{d}, \mathrm{J}=8.7 \mathrm{~Hz}, 1 \mathrm{H}), 7.98-7.89(\mathrm{~m}, 2 \mathrm{H}), 7.37-7.34(\mathrm{~m}, 2 \mathrm{H}), 7.31(\mathrm{t}, \mathrm{J}=4.9 \mathrm{~Hz}, 1 \mathrm{H}), 7.26-7.22$ $(\mathrm{m}, 1 \mathrm{H}), 7.18(\mathrm{t}, \mathrm{J}=8.6 \mathrm{~Hz}, 2 \mathrm{H}), 6.58(\mathrm{~d}, \mathrm{~J}=8.7 \mathrm{~Hz}, 1 \mathrm{H}), 5.56(\mathrm{~s}, 2 \mathrm{H}), 3.00-2.86(\mathrm{~m}, 2 \mathrm{H}), 2.67$ $(\mathrm{td}, \mathrm{J}=8.4,4.9 \mathrm{~Hz}, 2 \mathrm{H})$. 


\section{Ethyl 3-((2,6-dichlorobenzyl)oxy)-9a-((4-fluorophenyl)sulfonyl)-6,6a,7,8,9,9a-hexahydro-}

$5 H$-cyclopenta[ $f]$ quinoline-7-carboxylate (12).

A solution of $11(17.1 \mathrm{~g}, 36.8 \mathrm{mmol})$ and ethyl 4-chlorobutanoate $(21.0 \mathrm{~mL}, 147 \mathrm{mmol})$ in THF $(184 \mathrm{~mL})$ was cooled to $-78{ }^{\circ} \mathrm{C}$ and treated over 30 min with lithium bis(trimethylsilyl)amide (1.0 M in THF; $147 \mathrm{~mL}, 147 \mathrm{mmol})$. The resulting mixture was stirred for $2 \mathrm{~h}$, then allowed to warm to $\mathrm{rt}$. After $18 \mathrm{~h}$, the mixture was cooled to $0{ }^{\circ} \mathrm{C}$ and treated with saturated aq $\mathrm{NH}_{4} \mathrm{Cl}$. The mixture was concentrated to about half volume, then partitioned between ether and saturated aq $\mathrm{NH}_{4} \mathrm{Cl}$. The organic phase was washed with saturated aq $\mathrm{NH}_{4} \mathrm{Cl}$ and brine, dried over $\mathrm{MgSO}_{4}$ and concentrated. The residue was triturated with ether, and the suspension was stirred at $0{ }^{\circ} \mathrm{C}$ for $30 \mathrm{~min}$. The precipitate was collected by filtration, washed with cold ether and dried to provide $\mathbf{1 2}$ (mixture of diastereomers) as a light brown solid (7.83 g). The filtrate was concentrated, and the residue was purified by column chromatography on silica gel (330 g), eluting with EtOAc-hexanes (gradient from 5-25\%), to provide additional 12 as an off-white glassy solid (7.68 g, total 73\% yield). HPLC $t_{\mathrm{R}} 1.24 \mathrm{~min}$ (method A). LCMS m/z calcd for $\mathrm{C}_{28} \mathrm{H}_{27} \mathrm{Cl}_{2} \mathrm{FNO}_{5} \mathrm{~S}[\mathrm{M}+\mathrm{H}]^{+}$578.1, 580.1; obsd 578.5, 580.5. ${ }^{1} \mathrm{H}$ NMR $(499 \mathrm{MHz}$, $\left.\mathrm{CDCl}_{3}\right) \delta 7.68(\mathrm{~d}, \mathrm{~J}=8.6 \mathrm{~Hz}, 1 \mathrm{H}), 7.41-7.34(\mathrm{~m}, 4 \mathrm{H}), 7.29-7.23(\mathrm{~m}, 1 \mathrm{H}), 7.05(\mathrm{t}, \mathrm{J}=8.6 \mathrm{~Hz}$, $2 \mathrm{H}), 6.67(\mathrm{~d}, \mathrm{~J}=8.7 \mathrm{~Hz}, 1 \mathrm{H}), 5.64-5.49(\mathrm{~m}, 2 \mathrm{H}), 4.23(\mathrm{q}, \mathrm{J}=7.2 \mathrm{~Hz}, 2 \mathrm{H}), 3.28(\mathrm{td}, \mathrm{J}=8.7,5.9 \mathrm{~Hz}$, $1 \mathrm{H}), 3.18(\mathrm{ddd}, \mathrm{J}=13.9,7.6,3.6 \mathrm{~Hz}, 1 \mathrm{H}), 2.73-2.65(\mathrm{~m}, 1 \mathrm{H}), 2.58(\mathrm{dt}, \mathrm{J}=16.9,5.2 \mathrm{~Hz}, 1 \mathrm{H}), 2.37$ (dtd, J=12.5, 9.8, 7.6 Hz, 1H), 2.16 (ddd, J=13.9, 10.0, 7.2 Hz, 1H), $2.11-2.01(\mathrm{~m}, 2 \mathrm{H}), 1.96$ (ddd, J=16.9, 9.8, 4.4 Hz, 1H), 1.45 (dtd, J=13.8, 9.3, 4.6 Hz, 1H), 1.32 (t, J=7.2 Hz, 3H).

\section{Ethyl 3-bromo-9a-((4-fluorophenyl)sulfonyl)-6,6a,7,8,9,9a-hexahydro-5H- cyclopenta[f]quinoline-7-carboxylate (13).}

A solution of $12(17.0 \mathrm{~g}, 29.4 \mathrm{mmol})$ in 1,2-dichloroethane $(147 \mathrm{~mL})$ was treated with $\mathrm{HCl}(4.0 \mathrm{M}$ in dioxane; $44.0 \mathrm{~mL}, 176 \mathrm{mmol})$ at $\mathrm{rt}$. The mixture was heated at $50{ }^{\circ} \mathrm{C}$. After $18 \mathrm{~h}$, the mixture was cooled to $\mathrm{rt}$ and concentrated. The residue was dissolved in DCM $(20 \mathrm{~mL})$ and added slowly to stirred ether $(400 \mathrm{~mL})$. The suspension was stirred for $30 \mathrm{~min}$, and the solid was collected by filtration, washed 3 times with ether, and dried under vacuum to provide a mixture of diastereomers of ethyl 9a-((4-fluorophenyl)sulfonyl)-3-hydroxy-6,6a,7,8,9,9a-hexahydro-5Hcyclopenta[f]quinoline-7-carboxylate (12.3 g). HPLC $t_{\mathrm{R}} 0.77 \mathrm{~min}$ (method A). LCMS $\mathrm{m} / \mathrm{z}$ calcd for $\mathrm{C}_{21} \mathrm{H}_{23} \mathrm{FNO}_{5} \mathrm{~S}[\mathrm{M}+\mathrm{H}]^{+}$420.1; obsd 420.4. ${ }^{1} \mathrm{H}$ NMR $\left(499 \mathrm{MHz}, \mathrm{MeOH}-\mathrm{d}_{4}\right) \delta 7.82(\mathrm{~d}, \mathrm{~J}=9.3$ $\mathrm{Hz}, 1 \mathrm{H}), 7.69-7.63(\mathrm{~m}, 2 \mathrm{H}), 7.35$ (t, J=8.8 Hz, 2H), 6.68 (d, J=9.4 Hz, 1H), 4.18 (q, J=7.2 Hz, 2H), $3.20(\mathrm{td}, \mathrm{J}=8.4,5.8 \mathrm{~Hz}, 1 \mathrm{H}), 2.97$ (ddd, J=13.8, 7.5, $4.4 \mathrm{~Hz}, 1 \mathrm{H}), 2.76(\mathrm{q}, \mathrm{J}=8.5 \mathrm{~Hz}, 1 \mathrm{H})$, $2.63-2.55(\mathrm{~m}, 1 \mathrm{H}), 2.24-2.16(\mathrm{~m}, 1 \mathrm{H}), 2.15-2.03(\mathrm{~m}, 3 \mathrm{H}), 2.02-1.94(\mathrm{~m}, 1 \mathrm{H}), 1.62-1.46(\mathrm{~m}$, $1 \mathrm{H}), 1.27(\mathrm{t}, \mathrm{J}=7.2 \mathrm{~Hz}, 3 \mathrm{H})$.

A solution of this material $(12.3 \mathrm{~g}, 29.3 \mathrm{mmol})$ and pyridine $(4.75 \mathrm{~mL}, 58.6 \mathrm{mmol})$ in DCM $(147 \mathrm{~mL})$ was cooled to $0{ }^{\circ} \mathrm{C}$ and treated over 30 min with trifluoromethanesulfonic anhydride $(7.40 \mathrm{~mL}, 44.0 \mathrm{mmol})$. The cold mixture was stirred for $1 \mathrm{~h}$, treated with additional pyridine $(1.2 \mathrm{~mL}, 14.7 \mathrm{mmol})$ and trifluoromethanesulfonic anhydride $(1.5 \mathrm{~mL}, 8.8 \mathrm{mmol})$, and stirred for $1.5 \mathrm{~h}$ more. The mixture was treated with saturated aq $\mathrm{NH}_{4} \mathrm{Cl}(2 \mathrm{~mL})$, diluted with EtOAc, washed with water and brine, dried over $\mathrm{Na}_{2} \mathrm{SO}_{4}$, and concentrated to provide ethyl 9a((4-fluorophenyl)sulfonyl)-3-(((trifluoromethyl)sulfonyl)oxy)-6,6a, 7,8,9,9a-hexahydro-5Hcyclopenta[f]quinoline-7-carboxylate (mixture of diastereomers; $15.5 \mathrm{~g}, 96 \%$ yield for 2 steps). HPLC $t_{\mathrm{R}} 1.11 \mathrm{~min}$ (method A). LCMS $m / z$ calcd for $\mathrm{C}_{22} \mathrm{H}_{22} \mathrm{~F}_{4} \mathrm{NO}_{7} \mathrm{~S}_{2}[\mathrm{M}+\mathrm{H}]^{+} 552.1$; obsd 552.4. ${ }^{1} \mathrm{H}$ NMR $\left(499 \mathrm{MHz}, \mathrm{CDCl}_{3}\right) \delta 8.03(\mathrm{~d}, \mathrm{~J}=8.5 \mathrm{~Hz}, 1 \mathrm{H}), 7.32$ - $7.28(\mathrm{~m}, 2 \mathrm{H}), 7.12$ - $7.07(\mathrm{~m}, 3 \mathrm{H})$, 
$4.24(\mathrm{q}, \mathrm{J}=7.3 \mathrm{~Hz}, 2 \mathrm{H}), 3.36-3.26(\mathrm{~m}, 2 \mathrm{H}), 2.73-2.65(\mathrm{~m}, 1 \mathrm{H}), 2.65-2.56(\mathrm{~m}, 1 \mathrm{H}), 2.46-2.38$ $(\mathrm{m}, 1 \mathrm{H}), 2.20-2.10(\mathrm{~m}, 3 \mathrm{H}), 1.86(\mathrm{ddd}, \mathrm{J}=16.9,11.7,5.2 \mathrm{~Hz}, 1 \mathrm{H}), 1.43-1.36(\mathrm{~m}, 1 \mathrm{H}), 1.32(\mathrm{t}$, $\mathrm{J}=7.2 \mathrm{~Hz}, 3 \mathrm{H})$.

A vigorously stirred solution of this material $(15.5 \mathrm{~g}, 28.1 \mathrm{mmol})$ in DCM $(20 \mathrm{~mL})$ and toluene $(160 \mathrm{~mL})$ was treated with $\mathrm{LiBr}(11.0 \mathrm{~g}, 126 \mathrm{mmol})$, then was treated portionwise with $\mathrm{TsOH}(5.88 \mathrm{~g}, 30.9 \mathrm{mmol})$. The mixture was stirred at $50{ }^{\circ} \mathrm{C}$ for $16 \mathrm{~h}$. The mixture was cooled to rt, diluted with DCM and water, and the organic phase was separated and washed with brine, dried over $\mathrm{Na}_{2} \mathrm{SO}_{4}$, and concentrated. The residue was purified by column chromatography on silica gel (120 g), eluting with EtOAc-hexanes (gradient from 0-30\%), to provide 13 (mixture of diastereomers; $10.2 \mathrm{~g}, 75 \%$ yield). HPLC $t_{\mathrm{R}} 1.02 \mathrm{~min}$ (method A). LCMS $\mathrm{m} / \mathrm{z}$ calcd for $\mathrm{C}_{21} \mathrm{H}_{22} \mathrm{BrFNO}_{4} \mathrm{~S}[\mathrm{M}+\mathrm{H}]^{+}$482.1, 484.1; obsd 482.4, 484.4. ${ }^{1} \mathrm{H}$ NMR (499 MHz, $\left.\mathrm{CDCl}_{3}\right) \delta 7.67$ (d, $\mathrm{J}=8.3 \mathrm{~Hz}, 1 \mathrm{H}), 7.43-7.36(\mathrm{~m}, 3 \mathrm{H}), 7.15-7.09(\mathrm{~m}, 2 \mathrm{H}), 4.22(\mathrm{q}, \mathrm{J}=7.2 \mathrm{~Hz}, 2 \mathrm{H}), 3.30(\mathrm{td}, \mathrm{J}=8.8$, $5.9 \mathrm{~Hz}, 1 \mathrm{H}), 3.21(\mathrm{ddd}, \mathrm{J}=13.8,7.6,3.2 \mathrm{~Hz}, 1 \mathrm{H}), 2.70-2.63(\mathrm{~m}, 2 \mathrm{H}), 2.36(\mathrm{dtd}, \mathrm{J}=12.4,10.0,7.4$ $\mathrm{Hz}, 1 \mathrm{H}), 2.17$ - $1.99(\mathrm{~m}, 4 \mathrm{H}), 1.46-1.37$ (m, 1H), 1.31 (t, J=7.2 Hz, 3H).

\section{Activated copper powder.}

Activated copper was prepared by adding zinc dust (24.6 g, $376 \mathrm{mmol})$ portionwise with stirring to a solution of $\mathrm{CuSO}_{4}(45.1 \mathrm{~g}, 283 \mathrm{mmol})$ in water $(250 \mathrm{~mL})$ over $10 \mathrm{~min}$. The mixture was stirred 10 min longer, then the supernatant was decanted from the red precipitate, which was washed twice with water by decantation, then was stirred with $1 \mathrm{M}$ aq $\mathrm{HCl}(400 \mathrm{~mL})$ for $2.5 \mathrm{~h}$. The supernatant was decanted and the precipitate was washed repeatedly by decantation after stirring with fresh water until the $\mathrm{pH}$ of the supernatant was about 7 . The solid was stored under water and an inert atmosphere (nitrogen or argon). Immediately before use, a sample of the solid was washed twice by decantation from $\mathrm{MeOH}$, then twice by decantation from diethyl ether, and dried under vacuum.

\section{9a-((4-Fluorophenyl)sulfonyl)-3-(perfluoropropan-2-yl)-6,6a,7,8,9,9a-hexahydro-5H- cyclopenta[f]quinoline-7-carboxylic acid (14).}

A mixture of dried activated copper (15.8 g, $248 \mathrm{mmol}), \mathbf{1 3}(10.2 \mathrm{~g}, 21.2 \mathrm{mmol}), \mathrm{DMF}$ $(140 \mathrm{~mL})$, and perfluoro-2-iodopropane $(12 \mathrm{~mL}, 85 \mathrm{mmol})$ was sealed under nitrogen in a pressure vial and stirred at $120{ }^{\circ} \mathrm{C}$ for $2.5 \mathrm{~h}$. The mixture was cooled to $\mathrm{rt}$, mixed with water (300 $\mathrm{mL})$ and ether $(350 \mathrm{~mL})$, filtered through a Celite pad, and the solids were washed with ether. The combined filtrates were separated and the organic phase was washed with saturated aq $\mathrm{NaHCO}_{3}, 10 \%$ aq $\mathrm{LiCl}$ and brine, dried over $\mathrm{MgSO}_{4}$ and concentrated to afford a mixture of diastereomers of ethyl 9a-((4-fluorophenyl)sulfonyl)-3-(perfluoropropan-2-yl)-6,6a,7,8,9,9ahexahydro- $5 H$-cyclopenta[ $f$ ]quinoline-7-carboxylate as a sticky brown solid $(12.0 \mathrm{~g}$, quantitative yield), used without purification. HPLC $t_{\mathrm{R}} 1.14 \mathrm{~min}$ (method A). LCMS $\mathrm{m} / \mathrm{z}$ calcd for

$\mathrm{C}_{24} \mathrm{H}_{22} \mathrm{~F}_{8} \mathrm{NO}_{4} \mathrm{~S}[\mathrm{M}+\mathrm{H}]^{+}$572.1; obsd 572.2. ${ }^{1} \mathrm{H} \mathrm{NMR}\left(499 \mathrm{MHz}, \mathrm{CDCl}_{3}\right) \delta 8.01(\mathrm{~d}, \mathrm{~J}=8.2 \mathrm{~Hz}, 1 \mathrm{H})$, $7.60(\mathrm{dd}, \mathrm{J}=8.2,2.6 \mathrm{~Hz}, 1 \mathrm{H}), 7.23-7.17(\mathrm{~m}, 2 \mathrm{H}), 7.04-6.98(\mathrm{~m}, 2 \mathrm{H}), 4.28-4.23(\mathrm{~m}, 2 \mathrm{H}), 3.40$ $3.32(\mathrm{~m}, 2 \mathrm{H}), 2.74-2.63(\mathrm{~m}, 2 \mathrm{H}), 2.53-2.43(\mathrm{~m}, 1 \mathrm{H}), 2.25-2.14(\mathrm{~m}, 3 \mathrm{H}), 1.85-1.77(\mathrm{~m}, 2 \mathrm{H})$, $1.33(\mathrm{t}, \mathrm{J}=7.2 \mathrm{~Hz}, 3 \mathrm{H})$.

A mixture of this material $(12.0 \mathrm{~g}, 21.0 \mathrm{mmol})$ and $\mathrm{LiOH}$ monohydrate $(3.52 \mathrm{~g}, 84.0$ $\mathrm{mmol})$ in THF-EtOH-water $(3: 1: 1,175 \mathrm{~mL})$ was stirred at $\mathrm{rt}$ for $18 \mathrm{~h}$. The mixture was concentrated and the residue was partitioned between EtOAc and $0.5 \mathrm{M}$ aq $\mathrm{HCl}$. The organic phase was washed with brine, dried over $\mathrm{MgSO}_{4}$ and concentrated to provide 14, a mixture of diastereomers, as light yellow solid (11.4 g, quantitative yield), used without further purification. 
HPLC $t_{\mathrm{R}} 1.01 \mathrm{~min}$ (method A). LCMS $m / z$ calcd for $\mathrm{C}_{22} \mathrm{H}_{18} \mathrm{~F}_{8} \mathrm{NO}_{4} \mathrm{~S}[\mathrm{M}+\mathrm{H}]^{+}$544.1; obsd 544.3. ${ }^{1} \mathrm{H}$ NMR (499 MHz, DMSO-d 6 ) $\delta 12.67-12.06(\mathrm{~m}, 1 \mathrm{H}), 8.80(\mathrm{~s}, 1 \mathrm{H}), 7.93(\mathrm{~d}, \mathrm{~J}=8.2 \mathrm{~Hz}, 1 \mathrm{H})$, 7.77 (dd, J=8.3, 2.9 Hz, 1H), $7.32-7.27(\mathrm{~m}, 3 \mathrm{H}), 3.27-3.20(\mathrm{~m}, 1 \mathrm{H}), 3.05$ (ddd, J=14.1, 6.8, 2.2 $\mathrm{Hz}, 1 \mathrm{H}), 2.80-2.71(\mathrm{~m}, 1 \mathrm{H}), 2.61(\mathrm{dt}, \mathrm{J}=16.4,3.9 \mathrm{~Hz}, 1 \mathrm{H}), 2.30(\mathrm{~s}, 1 \mathrm{H}), 2.20-2.13(\mathrm{~m}, 1 \mathrm{H})$, $2.13-1.99(\mathrm{~m}, 3 \mathrm{H}), 1.42$ (br s, 1H).

2-(Trimethylsilyl)ethyl ((6aS,7R,9aS)-9a-((4-fluorophenyl)sulfonyl)-3-(perfluoropropan-2yl)-6,6a,7,8,9,9a-hexahydro-5 $H$-cyclopenta[f]quinolin-7-yl)carbamate (15).

A suspension of $\mathbf{1 4}(11.4 \mathrm{~g}, 21.0 \mathrm{mmol})$ in toluene $(210 \mathrm{~mL})$ at $0{ }^{\circ} \mathrm{C}$ was treated with $\mathrm{Et}_{3} \mathrm{~N}(5.85 \mathrm{~mL}, 42.0 \mathrm{mmol})$. The resulting solution was stirred at $0{ }^{\circ} \mathrm{C}$ for $5 \mathrm{~min}$, then was treated over $10 \mathrm{~min}$ with diphenyl phosphorazidate $(10.4 \mathrm{~mL}, 48.2 \mathrm{mmol})$. The mixture was stirred for 1 $\mathrm{h}$ at $0{ }^{\circ} \mathrm{C}$, then warmed to $\mathrm{rt}$ and stirred for $2 \mathrm{~h}$ more. The mixture was treated with water and extracted with EtOAc. The organic phase was washed with brine, dried over $\mathrm{MgSO}_{4}$ and concentrated. The residue was treated with 2-(trimethylsilyl)ethan-1-ol (75.0 mL, $524 \mathrm{mmol}$ ) and heated at $80{ }^{\circ} \mathrm{C}$ for $90 \mathrm{~min}$, then was cooled to rt. The mixture was partitioned between water and EtOAc, and the organic phase was washed with brine, dried over $\mathrm{MgSO}_{4}$ and concentrated. The residue was purified by column chromatography on silica gel (220 g), eluting with EtOAchexanes (gradient from 0-30\%), to provide a mixture of diastereomers of 2-(trimethylsilyl)ethyl (9a-((4-fluorophenyl)sulfonyl)-3-(perfluoropropan-2-yl)-6,6a, 7,8,9,9a-hexahydro-5 $\mathrm{H}$ cyclopenta[f]quinolin-7-yl)carbamate as a light yellow solid (15.0 g, 90\% purity).

A sample of this material (1.2 g) was dissolved in $\mathrm{MeOH}(17 \mathrm{~mL})$ and subjected to SFC using the following conditions: Column, $(\mathrm{R}, \mathrm{R})$ Whelk-O1 $(5 \times 50 \mathrm{~cm}, 10 \mu)$; temperature $35{ }^{\circ} \mathrm{C}$; mobile phase: $\mathrm{CO}_{2} / \mathrm{MeOH}$ (85:15); flow rate $300 \mathrm{~mL} / \mathrm{min}$; pressure 100 bar; $1 \mathrm{~mL}$ injections. Three fractions were collected. The second-eluting fractions were combined and concentrated to provide 15 ( $0.375 \mathrm{~g}, 31 \%$ yield). The absolute stereochemistry was proven by the conversion (via 16) to 8e and solution of the $X$-ray co-crystal structure of that compound in the LBD of ROR $\gamma$ t. HPLC $t_{\mathrm{R}} 1.23 \mathrm{~min}$ (method A). LCMS $\mathrm{m} / z$ calcd for $\mathrm{C}_{27} \mathrm{H}_{31} \mathrm{~F}_{8} \mathrm{~N}_{2} \mathrm{O}_{4} \mathrm{SSi}[\mathrm{M}+\mathrm{H}]^{+} 659.2$; obsd 659.0. ${ }^{1} \mathrm{H}$ NMR (499 MHz, CDCl3) $\delta 8.09$ (d, J=8.2 Hz, 1H), 7.62 (dd, J=8.3, $\left.2.6 \mathrm{~Hz}, 1 \mathrm{H}\right)$, 7.17 - 7.08 (m, 2H), 6.97 (t, J=8.5 Hz, 2H), 5.60 (br d, J=8.7 Hz, 1H), $4.26-4.06$ (m, 3H), 3.32 (dt, J=14.2, 7.0 Hz, 1H), 2.77 - $2.60(\mathrm{~m}, 2 \mathrm{H}), 2.31$ (dt, J=14.6, 7.4 Hz, 1H), $2.26-2.19$ (m, 1H), 2.19 - 2.07 (m, 2H), 1.70 - $1.59(\mathrm{~m}, 1 \mathrm{H}), 1.37$ (qd, J=12.8, 3.4 Hz, 1H), 1.07 - 1.00 (m, 2H), 0.07 (s, 9H).

\section{(6aS,7R,9aS)-9a-((4-Fluorophenyl)sulfonyl)-3-(perfluoropropan-2-yl)-6,6a,7,8,9,9a-} hexahydro-5H-cyclopenta[f]quinolin-7-amine $\mathrm{HCl}(16)$.

A solution of $15(0.375 \mathrm{~g}, 0.569 \mathrm{mmol})$ in 1,2-dichloroethane $(4.8 \mathrm{~mL})$ was cooled to 0 ${ }^{\circ} \mathrm{C}$ and treated with $\mathrm{HCl}$ (4.0 M in 1,4-dioxane; $\left.1.4 \mathrm{~mL}, 5.6 \mathrm{mmol}\right)$ and the mixture was stirred while heating at $40{ }^{\circ} \mathrm{C}$ for $6 \mathrm{~h}$. The mixture was cooled to $\mathrm{rt}$ and concentrated to provide $\mathbf{1 6}$ as a white solid ( $0.33 \mathrm{~g}$, quantitative yield). HPLC $t_{\mathrm{R}} 0.84 \mathrm{~min}$ (method A). LCMS $\mathrm{m} / z$ calcd for $\mathrm{C}_{21} \mathrm{H}_{19} \mathrm{~F}_{8} \mathrm{~N}_{2} \mathrm{O}_{2} \mathrm{~S}[\mathrm{M}+\mathrm{H}]^{+}$515.1; obsd 514.9.

$N$-((6aS,7R,9aS)-9a-((4-Fluorophenyl)sulfonyl)-3-(perfluoropropan-2-yl)-6,6a,7,8,9,9ahexahydro-5H-cyclopenta[f]quinolin-7-yl)-2-hydroxy-2-methylpropanamide (8a).

A mixture of 16 (25 mg, $0.045 \mathrm{mmol})$, HATU (31 mg, $0.082 \mathrm{mmol}), i$-PrNEt 2 (40 $\mu \mathrm{L}$, $0.227 \mathrm{mmol})$, and 2-hydroxy-2-methylpropanoic acid $(9.5 \mathrm{mg}, 0.091 \mathrm{mmol})$ in DMF $(570 \mu \mathrm{L})$ 
was stirred at $\mathrm{rt}$ for $3.5 \mathrm{~h}$. The mixture was purified by preparative HPLC (method $\mathrm{J}$ ) to provide $8 \mathbf{a}\left(15.3 \mathrm{mg}, 55 \%\right.$ yield). HPLC $t_{\mathrm{R}} 2.16 \mathrm{~min}, 98.7 \%$ (method B), $2.09 \mathrm{~min}, 98.8 \%$ (method C). LCMS $m / z$ calcd for $\mathrm{C}_{25} \mathrm{H}_{26} \mathrm{~F}_{8} \mathrm{~N}_{2} \mathrm{O}_{4} \mathrm{~S}[\mathrm{M}+\mathrm{H}]^{+} 601.1$; obsd 601.1. ${ }^{1} \mathrm{H}$ NMR (500 MHz, DMSO-d 6 ) $\delta 8.07$ (br d, J=8.2 Hz, 1H), 7.87 (br d, J=8.5 Hz, 1H), 7.78 (br d, J=7.6 Hz, 1H), 7.36 (br d, $\mathrm{J}=4.6 \mathrm{~Hz}, 2 \mathrm{H}), 7.29$ (br t, J=8.5 Hz, 2H), 5.51 (s, 1H), 3.99 (br t, J=7.8 Hz, 1H), 3.06 - 2.96 (m, 1H), $2.91-2.81(\mathrm{~m}, 1 \mathrm{H}), 2.69-2.58(\mathrm{~m}, 1 \mathrm{H}), 2.37-2.27(\mathrm{~m}, 1 \mathrm{H}), 2.09-1.90(\mathrm{~m}, 3 \mathrm{H}), 1.80$ (br dd, J=11.6, 8.5 Hz, 1H), $1.46-1.33$ (m, 1H), 1.27 (br d, J=16.8 Hz, 6H).

$N$-((6aS,7R,9aS)-9a-((4-Fluorophenyl)sulfonyl)-3-(perfluoropropan-2-yl)-6,6a,7,8,9,9ahexahydro-5H-cyclopenta[f]quinolin-7-yl)-3-hydroxy-3-methylbutanamide (8b).

The compound was synthesized in 53\% yield from 16 and 3-hydroxy-3-methylbutanoic acid according to the procedure used to synthesize 8a, following purification using HPLC method J. HPLC $t_{\mathrm{R}} 2.19 \mathrm{~min}, 93.4 \%$ (method B), $2.12 \mathrm{~min}, 97.8 \%$ (method C). LCMS $\mathrm{m} / z$ calcd for $\mathrm{C}_{26} \mathrm{H}_{27} \mathrm{~F}_{8} \mathrm{~N}_{2} \mathrm{O}_{4} \mathrm{~S}[\mathrm{M}+\mathrm{H}]^{+}$615.2; obsd 615.2. High resolution MS (ESI) $\mathrm{m} / z$ calcd for $\mathrm{C}_{26} \mathrm{H}_{27} \mathrm{~F}_{8} \mathrm{~N}_{2} \mathrm{O}_{4} \mathrm{~S}[\mathrm{M}+\mathrm{H}]^{+}$615.1558; obsd: 615.1552 (-0.98 ppm). ${ }^{1} \mathrm{H}$ NMR (500 MHz, DMSO-d 6 ) $\delta 8.13$ (br d, J=7.9 Hz, 1H), 7.97 (br d, J=8.2 Hz, 1H), 7.76 (br d, J=7.9 Hz, 1H), $7.36-7.27$ (m, $4 \mathrm{H}), 4.87(\mathrm{~s}, 1 \mathrm{H}), 4.03-3.95(\mathrm{~m}, 1 \mathrm{H}), 3.06-2.94(\mathrm{~m}, 1 \mathrm{H}), 2.81-2.72(\mathrm{~m}, 1 \mathrm{H}), 2.70-2.59(\mathrm{~m}$, 1H), 2.32 - $2.19(\mathrm{~m}, 3 \mathrm{H}), 2.12-1.93(\mathrm{~m}, 3 \mathrm{H}), 1.83-1.70(\mathrm{~m}, 1 \mathrm{H}), 1.42$ (br d, J=9.2 Hz, 1H), $1.17(\mathrm{~s}, 6 \mathrm{H}) .{ }^{13} \mathrm{C}$ NMR $\left(151 \mathrm{MHz}, \mathrm{DMSO}-d_{6}\right) \delta \mathrm{ppm} 24.57$ (s, $\left.1 \mathrm{C}\right) 29.86$ (s, $\left.1 \mathrm{C}\right) 29.93$ (s, $1 \mathrm{C}$ ) $30.22(\mathrm{~s}, 1 \mathrm{C}) 31.00(\mathrm{~s}, 1 \mathrm{C}) 33.72(\mathrm{~s}, 1 \mathrm{C}) 46.01(\mathrm{~s}, 1 \mathrm{C}) 48.89(\mathrm{~s}, 1 \mathrm{C}) 55.03(\mathrm{~s}, 1 \mathrm{C}) 68.98(\mathrm{~s}, 1$ C) $74.22(\mathrm{~s}, 1 \mathrm{C}) 88.71-92.45(\mathrm{~m}, 1 \mathrm{C}) 116.95(\mathrm{~d}, J=22.89 \mathrm{~Hz}, 2 \mathrm{C}) 117.31-123.46(\mathrm{~m}, 2 \mathrm{C})$ 120.09 (br d, $J=8.72 \mathrm{~Hz}, 1 \mathrm{C}) 131.64$ (d, $J=3.27 \mathrm{~Hz}, 1 \mathrm{C}) 132.10$ (s, 1 C) 133.41 (d, J=9.81 Hz, 2 C) $140.77(\mathrm{~s}, 1 \mathrm{C}) 144.93(\mathrm{~d}, J=26.16 \mathrm{~Hz}, 1 \mathrm{C}) 160.38(\mathrm{~d}, J=3.27 \mathrm{~Hz}, 1 \mathrm{C}) 165.98$ (d, J=255.04 $\mathrm{Hz}, 1 \mathrm{C}) 171.61$ (s, $1 \mathrm{C})$.

$N$-((6aS,7R,9aS)-9a-((4-Fluorophenyl)sulfonyl)-3-(perfluoropropan-2-yl)-6,6a,7,8,9,9ahexahydro-5H-cyclopenta[f]quinolin-7-yl)tetrahydro-2H-thiopyran-4-carboxamide 1,1dioxide (8c).

The compound was synthesized in 58\% yield from 16 and tetrahydro- $2 H$-thiopyran-4carboxylic acid 1,1-dioxide according to the procedure used to synthesize 8a, following purification using HPLC method J. HPLC $t_{\mathrm{R}} 2.10 \mathrm{~min}, 98.9 \%(\operatorname{method} \mathrm{B}), 2.14 \mathrm{~min}, 100 \%$ (method C). LCMS $m / z$ calcd for $\mathrm{C}_{27} \mathrm{H}_{27} \mathrm{~F}_{8} \mathrm{~N}_{2} \mathrm{O}_{5} \mathrm{~S}_{2}[\mathrm{M}+\mathrm{H}]^{+}$675.1; obsd 675.3. High resolution MS (ESI) $m / z$ calcd for $\mathrm{C}_{27} \mathrm{H}_{27} \mathrm{~F}_{8} \mathrm{~N}_{2} \mathrm{O}_{5} \mathrm{~S}_{2}[\mathrm{M}+\mathrm{H}]^{+} 675.1228$; obsd: 675.1225 (-0.51 ppm). ${ }^{1} \mathrm{H}$ NMR (500 MHz, DMSO-d 6 ) $\delta 8.22$ (br d, J=7.6 Hz, 1H), 7.99 (br d, J=8.2 Hz, 1H), 7.79 - 7.72 $(\mathrm{m}, 1 \mathrm{H}), 7.32(\mathrm{br} \mathrm{d}, \mathrm{J}=6.7 \mathrm{~Hz}, 4 \mathrm{H}), 3.98-3.88(\mathrm{~m}, 1 \mathrm{H}), 3.20-3.08(\mathrm{~m}, 4 \mathrm{H}), 3.08-2.93(\mathrm{~m}, 1 \mathrm{H})$, 2.80 (br d, J=5.2 Hz, 1H), 2.70 - 2.58 (m, 1H), 2.27 (br dd, J=14.3, $7.3 \mathrm{~Hz}, 1 \mathrm{H}), 2.17$ - 1.92 (m, $7 \mathrm{H}), 1.85-1.73(\mathrm{~m}, 1 \mathrm{H}), 1.44-1.31(\mathrm{~m}, 1 \mathrm{H})$. One proton is missing, presumably obscured by the water peak. ${ }^{13} \mathrm{C}$ NMR $\left(151 \mathrm{MHz}, \mathrm{DMSO}-d_{6}\right) \delta \mathrm{ppm} 24.67$ (s, $\left.1 \mathrm{C}\right) 27.50$ (s, $\left.1 \mathrm{C}\right) 27.83(\mathrm{~s}, 1$ C) $30.24(\mathrm{~s}, 1 \mathrm{C}) 30.75(\mathrm{~s}, 1 \mathrm{C}) 33.72(\mathrm{~s}, 1 \mathrm{C}) 40.54(\mathrm{~s}, 1 \mathrm{C}) 45.94(\mathrm{~s}, 1 \mathrm{C}) 49.92(\mathrm{~s}, 1 \mathrm{C}) 50.00$ (s, 1 C) 55.38 (s, 1 C) 74.32 (s, 1 C) 88.28 - $93.30(\mathrm{~m}, 1 \mathrm{C}) 116.94$ (d, J=21.80 Hz, 2 C) 117.65 123.40 (m, 2 C) 120.09 (br d, J=9.81 Hz, 1 C) 131.68 (d, J=3.27 Hz, 1 C) 132.08 (s, 1 C) 133.38 (d, J=9.81 Hz, 2 C) $140.80(\mathrm{~s}, 1 \mathrm{C}) 144.92(\mathrm{~d}, J=26.16 \mathrm{~Hz}, 1 \mathrm{C}) 159.53-165.60$ (m, 1 C) 166.82 (s, 1 C) $173.53(\mathrm{~s}, 1 \mathrm{C})$. 
Scheme S2. Synthesis of $17 \mathrm{a}$ and $17 \mathrm{~b}$

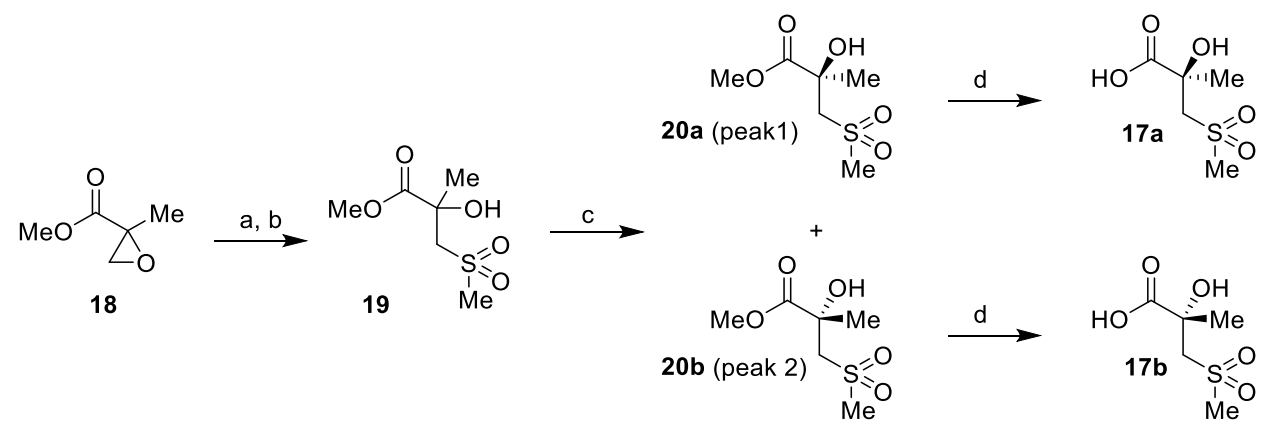

Reagents and conditions: (a) NaSMe, HOAc, MeOH, 98\%; (b) mCPBA, DCM, 80\%; (c) SFC, Chiralpak AD-H column, 49\% (20a), 47\% (20b); (d) LiOH, THF/MeOH/ $\mathrm{H}_{2} \mathrm{O}, \sim 100 \%$

\section{Methyl 2-hydroxy-2-methyl-3-(methylsulfonyl)propanoate (19).}

A solution of methyl 2-methyloxirane-2-carboxylate 18 (5.00 g, $42.6 \mathrm{mmol})$ and $\mathrm{AcOH}$ (3.05 mL, $53.3 \mathrm{mmol})$ in $\mathrm{MeOH}(125 \mathrm{~mL})$ was stirred at $5{ }^{\circ} \mathrm{C}$ and treated over about 5 min with sodium methanethiolate $(11.0 \mathrm{~g}, 149 \mathrm{mmol})$. After $10 \mathrm{~min}$, stirring was continued at $\mathrm{rt}$ for $2 \mathrm{~h}$. The mixture was cooled to about $5{ }^{\circ} \mathrm{C}$ and treated with acetic acid $(6.1 \mathrm{~mL}, 107 \mathrm{mmol})$. The mixture was concentrated and the residue was partitioned between ether and water. The aq phase was extracted twice with ether, and the combined organic phases were washed with saturated aq $\mathrm{NaHCO}_{3}$ and brine, dried over $\mathrm{Na}_{2} \mathrm{SO}_{4}$ and concentrated to give racemic methyl 2-hydroxy-2methyl-3-(methylthio)propionate as a pale yellow liquid $\left(6.87 \mathrm{~g}, 98 \%\right.$ yield). HPLC $t_{\mathrm{R}} 0.58 \mathrm{~min}$ (method A). LCMS m/z calcd for $\mathrm{C}_{6} \mathrm{H}_{12} \mathrm{O}_{3} \mathrm{~S}[\mathrm{M}+\mathrm{Na}]^{+}$187.0; obsd 186.9. ${ }^{1} \mathrm{H}$ NMR (499 MHz, $\left.\mathrm{CDCl}_{3}\right) \delta 3.85-3.78(\mathrm{~m}, 3 \mathrm{H}), 3.48(\mathrm{~s}, 1 \mathrm{H}), 2.97(\mathrm{~d}, \mathrm{~J}=14.1 \mathrm{~Hz}, 1 \mathrm{H}), 2.77(\mathrm{~d}, \mathrm{~J}=13.9 \mathrm{~Hz}, 1 \mathrm{H})$, $2.18(\mathrm{~s}, 3 \mathrm{H}), 1.49$ (s, 3H).

A solution of this material $(8.00 \mathrm{~g}, 48.7 \mathrm{mmol})$ in DCM $(400 \mathrm{~mL})$ was stirred at $0{ }^{\circ} \mathrm{C}$ and treated with mCPBA (33.6 g, $146 \mathrm{mmol})$ over about $5 \mathrm{~min}$. After $5 \mathrm{~min}$ more, additional mCPBA (11.2 g, $48.7 \mathrm{mmol})$ was added. Stirring was continued for $5 \mathrm{~min}$ more, then the mixture was stirred at $\mathrm{rt}$ for $1.75 \mathrm{~h}$. The solid was removed by filtration and rinsed with DCM. The combined filtrates were cooled to $0{ }^{\circ} \mathrm{C}$ and treated slowly with aq $\mathrm{Na}_{2} \mathrm{~S}_{2} \mathrm{O}_{3}(20 \mathrm{~g}$ in $125 \mathrm{~mL})$. After thorough mixing, the layers were separated and the aq phase was extracted with DCM. The combined organic phases were washed with saturated aq $\mathrm{NaHCO}_{3}$ and water, and these two aq phases were combined and extracted again with DCM. The combined organic phases were dried over $\mathrm{Na}_{2} \mathrm{SO}_{4}$, filtered and concentrated to provide $19(6.98 \mathrm{~g})$. Further extraction of the aq phases after saturation with $\mathrm{NaCl}$ provide additional 19 (total $9.21 \mathrm{~g}, 80 \%$ yield). HPLC $t_{\mathrm{R}} 0.42 \mathrm{~min}$ (method A). LCMS $m / z$ calcd for $\mathrm{C}_{6} \mathrm{H}_{12} \mathrm{O}_{5} \mathrm{~S}[\mathrm{M}+\mathrm{Na}]^{+}$219.0; obsd 219.1. ${ }^{1} \mathrm{H}$ NMR $(499 \mathrm{MHz}$, $\left.\mathrm{CDCl}_{3}\right) \delta 3.88(\mathrm{~s}, 3 \mathrm{H}), 3.61(\mathrm{dd}, \mathrm{J}=15.1,1.0 \mathrm{~Hz}, 1 \mathrm{H}), 3.44$ (d, J=15.0 Hz, 1H), 3.06 (s, 3H), 1.52 $(\mathrm{s}, 3 \mathrm{H})$. The exchangeable $\mathrm{OH}$ proton was not seen in the NMR.

\section{Methyl (R)-2-hydroxy-2-methyl-3-(methylsulfonyl)propanoate (20a) and methyl (S)-2-} hydroxy-2-methyl-3-(methylsulfonyl)propanoate (20b).

A sample of 19 (25.3 g,) was dissolved in DCM (40 mL) and isMeOH (250) and separated into its enantiomers by preparative SFC using the following conditions: Column, Chiralpak AD-H (5 x $25 \mathrm{~cm}, 5 \mu)$; temperature $40{ }^{\circ} \mathrm{C}$; mobile phase: $\mathrm{CO}_{2} / \mathrm{MeOH}(82: 18)$; flow 
rate $290 \mathrm{~mL} / \mathrm{min}$; pressure $100 \mathrm{bar}$; $0.7 \mathrm{~mL}$ injections. The first-eluted peaks from all injections were combined and concentrated to provide 20a (12.3 g, $49 \%$ yield) as a white solid. The second-eluted peaks from all injections were combined and concentrated to provide $\mathbf{2 0 b}$ (11.9 g, $47 \%$ yield) as a white solid. HPLC, LCMS and NMR for both enantiomers were identical to those of the racemate. The absolute stereochemistry of $\mathbf{2 0 b}$ was proven by the conversion (via 17b) to 8e and solution of the X-ray co-crystal structure of that compound in the LBD of ROR $\gamma \mathrm{t}$.

\section{(R)-2-Hydroxy-2-methyl-3-(methylsulfonyl)propanoic acid (17a) and (S)-2-hydroxy-2- methyl-3-(methylsulfonyl)propanoic acid (17b)}

A solution of $20 \mathrm{a}(2.00 \mathrm{~g}, 10.2 \mathrm{mmol})$ in THF $(50 \mathrm{~mL})$ and $\mathrm{MeOH}(17 \mathrm{~mL})$ was stirred at $0{ }^{\circ} \mathrm{C}$ and treated with a solution of $\mathrm{LiOH}$ hydrate $(0.684 \mathrm{~g}, 16.3 \mathrm{mmol})$ in water $(17 \mathrm{~mL})$. The mixture was stirred at $\mathrm{rt}$ for $90 \mathrm{~min}$, then was cooled to $0{ }^{\circ} \mathrm{C}$ and treated with $1 \mathrm{M}$ aq $\mathrm{HCl}(16.3$ $\mathrm{mL}, 16.3 \mathrm{mmol}$ ) and concentrated under vacuum to remove the bulk of the organic solvents. The aq residue was lyophilized to provide $\mathbf{1 7} \mathbf{a}$ as a white solid containing $\mathrm{LiCl}$ and residual water ( $2.75 \mathrm{~g}$, estimated $67 \%$ pure, quantitative yield), used without further purification. HPLC $t_{\mathrm{R}} 0.18$ min (method A). LCMS $m / z$ calcd for $\mathrm{C}_{5} \mathrm{H}_{9} \mathrm{O}_{5} \mathrm{~S}[\mathrm{M}-\mathrm{H}]^{-}$181.0; obsd 181.1. ${ }^{1} \mathrm{H}$ NMR (499 MHz, DMSO-d $)) \delta 3.53-3.37(\mathrm{~m}, 2 \mathrm{H}), 3.00(\mathrm{~s}, 3 \mathrm{H}), 1.37(\mathrm{~s}, 3 \mathrm{H})$. Two exchangeable protons, $\mathrm{COOH}$ and $\mathrm{OH}$, were not seen in the NMR.

Using the same procedure, 20b was converted into 17b. HPLC, LCMS and NMR were identical to those of $\mathbf{1 7 a}$.

(R)- $N$-((6aS,7R,9aS)-9a-((4-Fluorophenyl)sulfonyl)-3-(perfluoropropan-2-yl)-6,6a,7,8,9,9ahexahydro-5H-cyclopenta[f]quinolin-7-yl)-2-hydroxy-2-methyl-3(methylsulfonyl)propanamide $(8 \mathrm{~d})$.

The compound was synthesized in $64 \%$ yield from 16 and $17 \mathbf{a}$ according to the procedure used to synthesize 8a, following purification using HPLC method J. HPLC $t_{\mathrm{R}} 2.09 \mathrm{~min}, 100 \%$ (method B), 2.01 min, 99.4\% (method C). Chiral supercritical fluid chromatography (SFC) analysis: $t_{\mathrm{R}} 2.324 \mathrm{~min}$; enatiomeric excess (ee): 100\% [Column: Lux Cellulose (0.46 x $25 \mathrm{~cm}, 5$ $\mu \mathrm{m})$; Column Temp: $40{ }^{\circ} \mathrm{C}$; Flow: $3 \mathrm{~mL} / \mathrm{min}$; Mobile phase: $\mathrm{CO}_{2} / \mathrm{MeOH}=85: 15$; Injection volume: $5 \mu \mathrm{L}$; Detection: $240 \mathrm{~nm}, 280 \mathrm{~nm}]$. LCMS $m / z$ calcd for $\mathrm{C}_{26} \mathrm{H}_{27} \mathrm{~F}_{8} \mathrm{~N}_{2} \mathrm{O}_{6} \mathrm{~S}_{2}[\mathrm{M}+\mathrm{H}]^{+}$ 679.1; obsd 679.1. High resolution MS (ESI) $m / z$ calcd for $\mathrm{C}_{26} \mathrm{H}_{27} \mathrm{~F}_{8} \mathrm{~N}_{2} \mathrm{O}_{6} \mathrm{~S}_{2}[\mathrm{M}+\mathrm{H}]^{+} 679.1177$; obsd: 679.1179 (+0.28 ppm). ${ }^{1} \mathrm{H}$ NMR (500 MHz, DMSO-d $) \delta 8.08$ (br d, J=8.5 Hz, 1H), 7.87 (br d, J=8.5 Hz, 1H), 7.79 (br d, J=6.1 Hz, 1H), $7.39-7.27$ (m, 4H), $6.24(\mathrm{~s}, 1 \mathrm{H}), 4.06$ (br t, $\mathrm{J}=7.8 \mathrm{~Hz}, 1 \mathrm{H}), 3.54$ (br d, J=15.0 Hz, 1H), 3.34 (br s, 1H), 3.06 (m, 4H), 2.90 (br d, J=6.4 Hz, 1H), 2.63 (br d, J=16.8 Hz, 1H), $2.37-2.27$ (m, 1H), $2.15-1.79(\mathrm{~m}, 4 \mathrm{H}), 1.51$ (br d, J=9.5 Hz, 1H), 1.37 (s, 3H). ${ }^{13} \mathrm{C}$ NMR (151 MHz, DMSO-d6) $\delta$ ppm 24.60 (s, $\left.1 \mathrm{C}\right) 27.48$ (s, $\left.1 \mathrm{C}\right) 30.44(\mathrm{~s}$, 1 C) $30.87(\mathrm{~s}, 1 \mathrm{C}) 33.71(\mathrm{~s}, 1 \mathrm{C}) 43.99$ (s, 1 C) 46.34 (s, 1 C) 54.94 (s, 1 C) 62.57 (s, $1 \mathrm{C}) 72.76$ (s, 1 C) 74.69 (s, 1 C) 89.34 - 92.09 (m, 1 C) 116.83 (d, J=22.89 Hz, 2 C) 117.28 - 123.42 (m, 2 C) $120.08(\mathrm{~d}, J=8.72 \mathrm{~Hz}, 1 \mathrm{C}) 131.77$ (d, J=3.27 Hz, 1 C) 131.94 (s, 1 C) 133.43 (d, J=9.81 Hz, 2 C) $140.75(\mathrm{~s}, 1 \mathrm{C}) 144.92$ (d, J=26.16 Hz, 1 C) $160.31-160.45$ (m, 1 C) 165.95 (d, J=253.95 Hz, $1 \mathrm{C}) 173.93$ (s, $1 \mathrm{C})$. 
(S)- $N$-((6aS,7R,9aS)-9a-((4-Fluorophenyl)sulfonyl)-3-(perfluoropropan-2-yl)-6,6a,7,8,9,9ahexahydro-5H-cyclopenta[f]quinolin-7-yl)-2-hydroxy-2-methyl-3(methylsulfonyl)propanamide (8e).

The compound was synthesized in $72 \%$ yield from $\mathbf{1 6}$ and $\mathbf{1 7 b}$ according to the procedure used to synthesize 8a, following purification using HPLC method J. HPLC $t_{\mathrm{R}} 2.09 \mathrm{~min}, 100 \%$ (method B), $2.01 \mathrm{~min}, 100 \%$ (method C). Chiral supercritical fluid chromatography (SFC) analysis: $t_{\mathrm{R}} 3.157$ min, enatiomeric excess (ee): $100 \%$ [Column: Lux Cellulose $(0.46 \times 25 \mathrm{~cm}$, $5 \mu \mathrm{m}$ ); Column temp: $40{ }^{\circ} \mathrm{C}$; Flow: $3 \mathrm{~mL} / \mathrm{min}$; Mobile phase: $\mathrm{CO}_{2} / \mathrm{MeOH}=85: 15$; Injection volume: $5 \mu \mathrm{L}$; Detection: $240 \mathrm{~nm}, 280 \mathrm{~nm}]$. LCMS $m / z$ calcd for $\mathrm{C}_{26} \mathrm{H}_{27} \mathrm{~F}_{8} \mathrm{~N}_{2} \mathrm{O}_{6} \mathrm{~S}_{2}[\mathrm{M}+\mathrm{H}]^{+}$ 679.1; obsd 679.5. High resolution MS (ESI) $\mathrm{m} / \mathrm{z}$ calcd for $\mathrm{C}_{26} \mathrm{H}_{27} \mathrm{~F}_{8} \mathrm{~N}_{2} \mathrm{O}_{6} \mathrm{~S}_{2}[\mathrm{M}+\mathrm{H}]^{+} 679.1177$; obsd: 679.1168 (-1.39 ppm). ${ }^{1} \mathrm{H}$ NMR (500 MHz, DMSO- $\left.d_{6}\right) \delta$ ppm 1.42 (s, $\left.3 \mathrm{H}\right) 1.42-1.48(\mathrm{~m}$, $1 \mathrm{H}) 1.90(\mathrm{q}, J=7.21 \mathrm{~Hz}, 2 \mathrm{H}) 1.95-2.11(\mathrm{~m}, 1 \mathrm{H}) 1.99-2.06(\mathrm{~m}, 1 \mathrm{H}) 2.28-2.41(\mathrm{~m}, 1 \mathrm{H}) 2.59$ - $2.69(\mathrm{~m}, 1 \mathrm{H}) 2.87-2.97(\mathrm{~m}, 1 \mathrm{H}) 2.97-3.09(\mathrm{~m}, 3 \mathrm{H}) 2.97-3.06(\mathrm{~m}, 1 \mathrm{H}) 3.37-3.46(\mathrm{~m}, 1 \mathrm{H})$ $3.51-3.59(\mathrm{~m}, 1 \mathrm{H}) 3.98$ (quin, $J=7.27 \mathrm{~Hz}, 1 \mathrm{H}) 6.15(\mathrm{br} \mathrm{s}, 1 \mathrm{H}) 7.28$ - $7.35(\mathrm{~m}, 2 \mathrm{H}) 7.35$ - 7.42 (m, 2 H) $7.80(\mathrm{dd}, J=8.31,2.81 \mathrm{~Hz}, 1 \mathrm{H}) 8.03(\mathrm{br} \mathrm{d}, J=8.19 \mathrm{~Hz}, 1 \mathrm{H}) 8.09(\mathrm{~d}, J=8.31 \mathrm{~Hz}, 1 \mathrm{H})$. ${ }^{13} \mathrm{C}$ NMR (126 MHz, DMSO- $\left.d_{6}\right) \delta \mathrm{ppm} 24.76$ (s, $1 \mathrm{C}$ ) 27.52 (s, 1 C) 30.27 (br s, 1 C) 30.31 (s, 1 C) $33.70(\mathrm{~s}, 1 \mathrm{C}) 43.92(\mathrm{~s}, 1 \mathrm{C}) 45.82(\mathrm{~s}, 1 \mathrm{C}) 55.51(\mathrm{~s}, 1 \mathrm{C}) 62.50(\mathrm{~s}, 1 \mathrm{C}) 72.70(\mathrm{~s}, 1 \mathrm{C}) 74.73$ (s, 1 C) 88.78 - $92.41(\mathrm{~m}, 1 \mathrm{C}) 116.89$ (d, J=22.71 Hz, 2 C) 117.10 - 124.11 (m, 2 C) 120.09 (d, $J=8.17 \mathrm{~Hz}, 1 \mathrm{C}) 131.72$ (d, $J=2.72 \mathrm{~Hz}, 1 \mathrm{C}) 131.78(\mathrm{~s}, 1 \mathrm{C}) 133.43$ (d, $J=9.99 \mathrm{~Hz}, 2 \mathrm{C}) 140.86(\mathrm{~s}$, $1 \mathrm{C}) 144.95$ (d, $J=25.43 \mathrm{~Hz}, 1 \mathrm{C}) 160.52$ (d, $J=2.72 \mathrm{~Hz}, 1 \mathrm{C}) 165.97$ (d, $J=255.22 \mathrm{~Hz}, 1 \mathrm{C})$ 174.03 (s, $1 \mathrm{C}$ ). 
Scheme S3. Synthesis of Compounds 5a-b

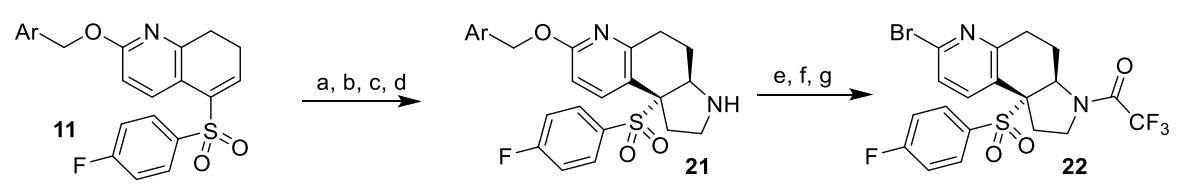

(Ar = 2,6-dichlorophenyl)

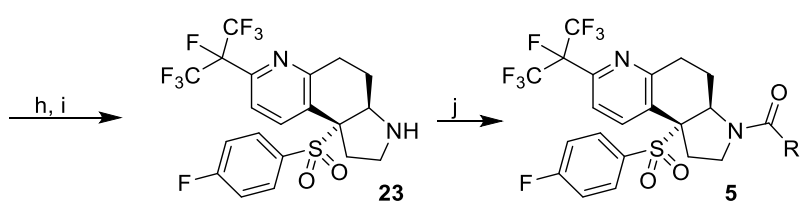

Reagents and conditions: (a) ethanolamine, THF, $0{ }^{\circ} \mathrm{C}$ to rt; (b) $\mathrm{MsCl}, \mathrm{Et}_{3} \mathrm{~N}, \mathrm{DCM}, 0{ }^{\circ} \mathrm{C}$ to $\mathrm{rt}$; (c) tert-BuOK, THF, rt, $37 \%$ for 3 steps; (d) SFC, ChromegaChiral CC4 column; (e) $\left(\mathrm{CF}_{3} \mathrm{CO}\right)_{2} \mathrm{O}$, pyridine, DCM, $0{ }^{\circ} \mathrm{C}$ to rt, $96 \%$; (f) $\mathrm{H}_{2}$, $\mathrm{Pd}-\mathrm{C}$, MeOH/EtOAc, rt, 100\%; (g) $\mathrm{POBr}_{3}, \mathrm{MeCN}$, anisole, $90{ }^{\circ} \mathrm{C}, 64 \%$; (h) activated $\mathrm{Cu}, \mathrm{IC}\left(\mathrm{CF}_{3}\right)_{2} \mathrm{~F}, \mathrm{DMF}, 120{ }^{\circ} \mathrm{C}$; (i) $\mathrm{LiOH}, \mathrm{THF} / \mathrm{H}_{2} \mathrm{O}, 85{ }^{\circ} \mathrm{C}$; (j) RCOOH, HATU, $i$-PrNEt 2 , DMF, 54-83\%.

\section{(3aR,9bR)-7-((2,6-Dichlorobenzyl)oxy)-9b-((4-fluorophenyl)sulfonyl)-2,3,3a,4,5,9b- hexahydro-1H-pyrrolo[3,2-f]quinoline (21).}

A solution of $\mathbf{1 1}(2.05 \mathrm{~g}, 4.41 \mathrm{mmol})$ in THF $(44 \mathrm{~mL})$ at $0{ }^{\circ} \mathrm{C}$ was treated with ethanolamine $(2.13 \mathrm{~mL}, 35.3 \mathrm{mmol})$ and stirred for $2 \mathrm{~h}$. The mixture was partitioned between saturated aq $\mathrm{NaHCO}_{3}$ and EtOAc, and the organic phase was washed with brine, dried over $\mathrm{MgSO}_{4}$ and concentrated to afford crude 2-((2-((2,6-dichlorobenzyl)oxy)-5-((4fluorophenyl)sulfonyl)-5,6,7,8-tetrahydroquinolin-6-yl)amino)ethan-1-ol as a pale brown glassy solid (2.21 g) used without purification. HPLC $t_{\mathrm{R}} 0.86 \mathrm{~min}$ (method A). LCMS $\mathrm{m} / z$ calcd for $\mathrm{C}_{24} \mathrm{H}_{24} \mathrm{Cl}_{2} \mathrm{FN}_{2} \mathrm{O}_{4} \mathrm{~S}[\mathrm{M}+\mathrm{H}]^{+}$525.1, 527.1; obsd 525.1, 527.0.

A solution of this material $(2.21 \mathrm{~g}, 4.21 \mathrm{mmol})$ in $\mathrm{DCM}(140 \mathrm{~mL})$ at $0{ }^{\circ} \mathrm{C}$ was treated slowly with methanesulfonyl chloride $(0.39 \mathrm{~mL}, 4.84 \mathrm{mmol})$, then with $\mathrm{Et}_{3} \mathrm{~N}(0.67 \mathrm{~mL}, 4.84$ $\mathrm{mmol})$. The mixture was stirred for $1.5 \mathrm{~h}$, then treated slowly with a solution of potassium tertbutoxide $(2.36 \mathrm{~g}, 21.0 \mathrm{mmol})$ in THF $(15 \mathrm{~mL})$. After $2 \mathrm{~h}$ more at $0{ }^{\circ} \mathrm{C}$ the mixture was partitioned between DCM and saturated aq $\mathrm{NaHCO}_{3}$. The organic phase was washed with brine, dried over $\mathrm{MgSO}_{4}$ and concentrated. The residue was purified by column chromatography on silica gel (80 g), eluting with EtOAc-hexanes (gradient from 50-100\%), then with 7\% MeOHEtOAc to provide racemic 7-((2,6-dichlorobenzyl)oxy)-9b-((4-fluorophenyl)sulfonyl)2,3,3a,4,5,9b-hexahydro- $1 H$-pyrrolo[3,2-f]quinoline as a light brown glassy solid $(0.78 \mathrm{~g}, 37 \%$ yield overall). HPLC $t_{\mathrm{R}} 0.87 \mathrm{~min}$ (method A). LCMS $m / z$ calcd for $\mathrm{C}_{24} \mathrm{H}_{22} \mathrm{Cl}_{2} \mathrm{FN}_{2} \mathrm{O}_{3} \mathrm{~S}[\mathrm{M}+\mathrm{H}]^{+}$ 507.1, 509.1; obsd 507.0, 509.0.

The enantiomers of this material $(0.78 \mathrm{~g})$ was separated by preparative SFC using the following conditions: Column, ChromegaChiral CC4 $(4.6 \times 250 \mathrm{~mm}, 5 \mu)$; temperature $40{ }^{\circ} \mathrm{C}$; mobile phase, $30 \% \mathrm{MeOH} / \mathrm{H}_{2} \mathrm{O}$ (95:5) in $\mathrm{CO}_{2}$; flow rate $3 \mathrm{~mL} / \mathrm{min}$; pressure 140 bar; $5 \mu \mathrm{L}$ injections. The second-eluted peaks from all injections were combined and concentrated to 
provide 21 as a light yellow solid $(0.297 \mathrm{~g})$. HPLC, LCMS identical to those of the racemic material.

The first-eluted peaks were combined and concentrated to afford $(3 \mathrm{a} S, 9 \mathrm{~b} S)-7-((2,6-$ dichlorobenzyl)oxy)-9b-((4-fluorophenyl)sulfonyl)-2,3,3a,4,5,9b-hexahydro-1H-pyrrolo[3,2$f$ ]quinoline as a light yellow solid $(0.273 \mathrm{~g})$. HPLC, LCMS identical to those of the racemic material.

The absolute configurations were assumed based on the lack of biological activity of final compounds derived from the first-eluting material.

\section{1-((3aR,9bR)-7-Bromo-9b-((4-fluorophenyl)sulfonyl)-1,2,3a,4,5,9b-hexahydro-3H- pyrrolo[3,2-f]quinolin-3-yl)-2,2,2-trifluoroethan-1-one (22).}

A solution of $21(0.297 \mathrm{~g}, 0.585 \mathrm{mmol})$ in DCM $(1.95 \mathrm{~mL})$ at $0{ }^{\circ} \mathrm{C}$ was treated with pyridine $(0.17 \mathrm{~mL}, 2.11 \mathrm{mmol})$ and trifluoroacetic anhydride $(0.13 \mathrm{~mL}, 0.937 \mathrm{mmol})$ and stirred at $\mathrm{rt}$ for $2 \mathrm{~h}$. The mixture was partitioned between ether and saturated aq $\mathrm{NH}_{4} \mathrm{Cl}$. The organic phase was washed with saturated aq $\mathrm{NaHCO}_{3}$ and brine, dried and concentrated. Toluene (10 $\mathrm{mL})$ was added to the residue and removed under vacuum to give $1-((3 \mathrm{a} R, 9 \mathrm{~b} R)-7-((2,6-$ dichlorobenzyl)oxy)-9b-((4-fluorophenyl)sulfonyl)-1,2,3a,4,5,9b-hexahydro-3H-pyrrolo[3,2$f$ lquinolin-3-yl)-2,2,2-trifluoroethan-1-one as a pale yellow solid $\left(0.340 \mathrm{~g}, 96 \%\right.$ yield). HPLC $t_{\mathrm{R}}$ 1.19 min (method A). LCMS $m / z$ calcd for $\mathrm{C}_{26} \mathrm{H}_{21} \mathrm{Cl}_{2} \mathrm{~F}_{4} \mathrm{~N}_{2} \mathrm{O}_{4} \mathrm{~S}[\mathrm{M}+\mathrm{H}]^{+}$603.1, 605.1; obsd 603.3, 605.3.

A solution of this material $(0.340 \mathrm{~g}, 0.563 \mathrm{mmol})$ in $\mathrm{MeOH}(19 \mathrm{~mL})$ was treated with $10 \% \mathrm{Pd}-\mathrm{C}(0.144 \mathrm{~g})$ and stirred under $\mathrm{H}_{2}(1 \mathrm{~atm})$ for $18 \mathrm{~h}$. The mixture was filtered and the filtrates were concentrated to afford 2,2,2-trifluoro-1-((3aR,9bR)-9b-((4-fluorophenyl)sulfonyl)7-hydroxy-1,2,3a,4,5,9b-hexahydro-3H-pyrrolo[3,2-f]quinolin-3-yl)ethan-1-one as a white solid $\left(0.250 \mathrm{~g}\right.$, quantitative yield). HPLC $t_{\mathrm{R}} 0.76 \mathrm{~min}$ (method A). LCMS $\mathrm{m} / \mathrm{z}$ calcd for $\mathrm{C}_{19} \mathrm{H}_{17} \mathrm{~F}_{4} \mathrm{~N}_{2} \mathrm{O}_{4} \mathrm{~S}[\mathrm{M}+\mathrm{H}]^{+} 445.1$; obsd 445.0.

A solution of this material $(0.250 \mathrm{~g}, 0.563 \mathrm{mmol})$ in $\mathrm{MeCN}(2.1 \mathrm{~mL})$ was treated with a solution of $\mathrm{POBr}_{3}(0.420 \mathrm{~g}, 1.46 \mathrm{mmol})$ in anisole $(1.04 \mathrm{~mL})$ and heated at $90{ }^{\circ} \mathrm{C}$ for $6 \mathrm{~h}$. After cooling to rt the mixture was poured on ice, neutralized with $1 \mathrm{M}$ aq $\mathrm{NaOH}(3.9 \mathrm{~mL}, 3.9 \mathrm{mmol})$ and saturated aq $\mathrm{NaHCO}_{3}$, and extracted with ether. The organic phase was washed with brine, dried over $\mathrm{MgSO}_{4}$ and concentrated. The residue was purified by column chromatography on silica gel (24 g), eluting with EtOAc-hexanes (gradient from 10-20\%) to provide 22 as a white solid $\left(0.183 \mathrm{~g}, 64 \%\right.$ yield). HPLC $t_{\mathrm{R}} 0.98 \mathrm{~min}(\operatorname{method} \mathrm{A})$. LCMS $\mathrm{m} / \mathrm{z}$ calcd for $\mathrm{C}_{19} \mathrm{H}_{16} \mathrm{BrF}_{4} \mathrm{~N}_{2} \mathrm{O}_{3} \mathrm{~S}[\mathrm{M}+\mathrm{H}]^{+}$507.0, 509.0; obsd 507.0, 509.0.

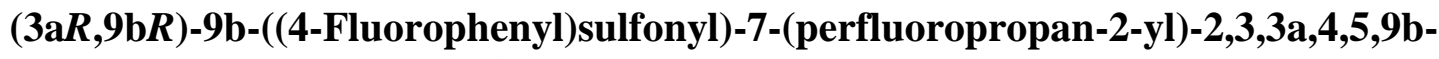 hexahydro-1H-pyrrolo[3,2-f]quinoline (23).}

To a sample of dry activated copper powder $(0.344 \mathrm{~g}, 5.41 \mathrm{mmol})$ in a pressure vial was added a solution of $22(0.183 \mathrm{~g}, 0.361 \mathrm{mmol})$ in dry DMF (3 mL) and perfluoro-2-iodopropane $(0.230 \mathrm{~mL}, 1.62 \mathrm{mmol})$. The vial was sealed under nitrogen and heated to $120^{\circ} \mathrm{C}$ for $2 \mathrm{~h}$. The mixture was cooled to rt and filtered through a Celite pad. The solids were washed with ether, and the combined filtrates were partitioned between ether and saturated aq $\mathrm{NaHCO}_{3}$. The organic phase was washed with $10 \%$ aq $\mathrm{LiCl}$ and brine, dried over $\mathrm{MgSO}_{4}$ and concentrated to afford 2,2,2-trifluoro-1-((3aR,9bR)-9b-((4-fluorophenyl)sulfonyl)-7-(perfluoropropan-2-yl)1,2,3a,4,5,9b-hexahydro-3H-pyrrolo[3,2-f] quinolin-3-yl)ethan-1-one as a brown solid (302 mg), 
used without purification. HPLC $t_{\mathrm{R}} 1.12 \mathrm{~min}$ (method A). LCMS $m / z$ calcd for $\mathrm{C}_{22} \mathrm{H}_{16} \mathrm{~F}_{11} \mathrm{~N}_{2} \mathrm{O}_{3} \mathrm{~S}$ $[\mathrm{M}+\mathrm{H}]^{+}$597.1; obsd 597.0.

A solution of this material $(0.300 \mathrm{~g}, 0.357 \mathrm{mmol})$ in THF $(2.4 \mathrm{~mL})$ was treated with a solution of LiOH hydrate $(0.150 \mathrm{~g}, 3.57 \mathrm{mmol})$ in water $(1.2 \mathrm{~mL})$ and heated at $85{ }^{\circ} \mathrm{C}$ for $4.5 \mathrm{~h}$. The mixture was cooled to rt and partitioned between EtOAc and water. The organic phase was washed with brine, dried over $\mathrm{MgSO}_{4}$ and concentrated to afford 23 as a light yellow solid (179 $\mathrm{mg}$, quantitative yield), used without purification. HPLC $t_{\mathrm{R}} 0.84 \mathrm{~min}$ (method A). LCMS $\mathrm{m} / z$ calcd for $\mathrm{C}_{20} \mathrm{H}_{17} \mathrm{~F}_{8} \mathrm{~N}_{2} \mathrm{O}_{2} \mathrm{~S}[\mathrm{M}+\mathrm{H}]^{+}$501.1; obsd 501.0.

\section{(1,1-Dioxidotetrahydro-2H-thiopyran-4-yl)((3aR,9bR)-9b-((4-fluorophenyl)sulfonyl)-7-} (perfluoropropan-2-yl)-1,2,3a,4,5,9b-hexahydro-3H-pyrrolo[3,2-f]quinolin-3-yl)methanone (5a).

The compound was synthesized from 23 and tetrahydro- $2 H$-thiopyran-4-carboxylic acid 1,1-dioxide according to the procedures used to synthesize 8a, and purified using HPLC method H. HPLC $t_{\mathrm{R}} 2.05 \mathrm{~min}, 99.2 \%$ (method B), $2.02 \mathrm{~min}, 99.0 \%$ (method C). LCMS $\mathrm{m} / z$ calcd for $\mathrm{C}_{26} \mathrm{H}_{25} \mathrm{~F}_{8} \mathrm{~N}_{2} \mathrm{O}_{5} \mathrm{~S}_{2}[\mathrm{M}+\mathrm{H}]^{+}$661.1; obsd 661.3. High resolution MS (ESI) $m / z$ calcd for $\mathrm{C}_{26} \mathrm{H}_{25} \mathrm{~F}_{8} \mathrm{~N}_{2} \mathrm{O}_{5} \mathrm{~S}_{2}[\mathrm{M}+\mathrm{H}]^{+}$661.1072; obsd: 661.1086 (+2.23 ppm). ${ }^{1} \mathrm{H}$ NMR (500 MHz, DMSOd6) $\delta 8.28(\mathrm{~d}, \mathrm{~J}=8.3 \mathrm{~Hz}, 1 \mathrm{H}), 7.82($ br d, J=8.1 Hz, 1H), $7.37(\mathrm{dd}, \mathrm{J}=8.5,5.1 \mathrm{~Hz}, 2 \mathrm{H}), 7.25$ (br t, $\mathrm{J}=8.4 \mathrm{~Hz}, 2 \mathrm{H}), 4.72$ (br dd, J=11.8, $5.0 \mathrm{~Hz}, 1 \mathrm{H}), 3.80-3.74(\mathrm{~m}, 2 \mathrm{H}), 3.20-3.05(\mathrm{~m}, 4 \mathrm{H}), 2.83-$ $2.72(\mathrm{~m}, 2 \mathrm{H}), 2.61$ (br d, J=17.3 Hz, 1H), $2.37-2.30(\mathrm{~m}, 1 \mathrm{H}), 2.13-1.95(\mathrm{~m}, 6 \mathrm{H}), 1.42$ (q, $\mathrm{J}=11.9 \mathrm{~Hz}, 1 \mathrm{H}) .{ }^{13} \mathrm{C}$ NMR $\left(176 \mathrm{MHz}, \mathrm{DMSO}-d_{6}\right) \delta \mathrm{ppm} 25.49(\mathrm{~s}, 1 \mathrm{C}) 26.71(\mathrm{~s}, 1 \mathrm{C}) 27.36(\mathrm{~s}, 1$ C) $30.56(\mathrm{~s}, 1 \mathrm{C}) 33.01(\mathrm{~s}, 1 \mathrm{C}) 37.92(\mathrm{~s}, 1 \mathrm{C}) 45.38(\mathrm{~s}, 1 \mathrm{C}) 49.96(\mathrm{~s}, 1 \mathrm{C}) 50.00(\mathrm{~s}, 1 \mathrm{C}) 59.08$ (s, 1 C) 74.29 (s, 1 C) 88.06 - $93.00(\mathrm{~m}, 1 \mathrm{C}) 117.06$ (d, J=22.89 Hz, 1 C) 117.50 - 122.94 (m, 2 C) $120.35(\mathrm{~d}, J=9.54 \mathrm{~Hz}, 1 \mathrm{C}) 131.17(\mathrm{~s}, 1 \mathrm{C}) 131.42$ (d, J=3.18 Hz, 1 C) 133.13 (d, J=10.17 Hz, 2 C) $140.66(\mathrm{~s}, 2 \mathrm{C}) 145.21(\mathrm{~d}, J=25.43 \mathrm{~Hz}, 1 \mathrm{C}) 159.45$ (d, J=2.54 Hz, 1 C) 165.94 (d, J=255.58 $\mathrm{Hz}, 1 \mathrm{C}) 172.46$ (s, $1 \mathrm{C})$.

3-((S)-2-((3aR,9bR)-9b-((4-Fluorophenyl)sulfonyl)-7-(perfluoropropan-2-yl)-2,3,3a,4,5,9bhexahydro-1H-pyrrolo[3,2-f]quinoline-3-carbonyl)-5-oxopyrrolidin-1-yl)propanenitrile, (5b).

The compound was synthesized from 23 and (S)-1-(2-cyanoethyl)-5-oxopyrrolidine-2carboxylic acid $^{2}$ according to the procedures used to synthesize 8a, and purified using HPLC method K. HPLC $t_{\mathrm{R}} 9.28 \mathrm{~min}, 98.9 \%$ (method D), $8.77 \mathrm{~min}, 99.1 \%$ (method E). LCMS $\mathrm{m} / \mathrm{z}$ calcd for $\mathrm{C}_{28} \mathrm{H}_{25} \mathrm{~F}_{8} \mathrm{~N}_{4} \mathrm{O}_{4} \mathrm{~S}[\mathrm{M}+\mathrm{H}]^{+}$665.1; obsd 665.2. ${ }^{1} \mathrm{H}$ NMR (499 MHz, MeOH-d 4 ) $\delta 8.46-$ $8.29(\mathrm{~m}, 1 \mathrm{H}), 7.81(\mathrm{dd}, \mathrm{J}=8.4,2.6 \mathrm{~Hz}, 1 \mathrm{H}), 7.47$ - $7.36(\mathrm{~m}, 2 \mathrm{H}), 7.17(\mathrm{t}, \mathrm{J}=8.7 \mathrm{~Hz}, 2 \mathrm{H}), 4.99$ $4.82(\mathrm{~m}, 2 \mathrm{H}), 4.19-3.35(\mathrm{~m}, 5 \mathrm{H}), 2.92$ - $2.36(\mathrm{~m}, 8 \mathrm{H}), 2.33-1.98(\mathrm{~m}, 2 \mathrm{H}), 1.89-1.45(\mathrm{~m}, 1 \mathrm{H})$. 
Scheme S4. Synthesis of Compounds 6a-b

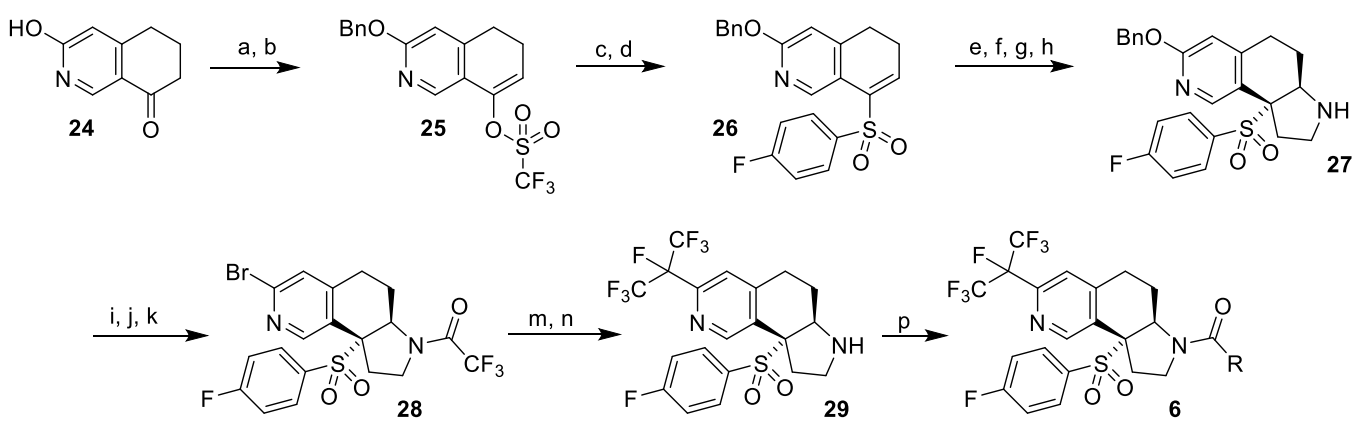

Reagents and conditions: (a) $\mathrm{BnBr}, \mathrm{Ag}_{2} \mathrm{CO}_{3}$, toluene, rt, $89 \%$; (b) $\left(\mathrm{CF}_{3} \mathrm{SO}_{2}\right)_{2} \mathrm{NPh}$, KHMDS, -78 ${ }^{\circ} \mathrm{C}$, 99\%; (c) 4-fluorobenzenethiol, $\mathrm{Pd}_{2}(\mathrm{dba})_{3}$, xantphos, $i$-PrNEt 2 , dioxane, $120{ }^{\circ} \mathrm{C}$; (d) mCPBA, $\mathrm{DCM}, 0{ }^{\circ} \mathrm{C}$ to rt, $89 \%$ for 2 steps; (e) ethanolamine, THF, $0{ }^{\circ} \mathrm{C}$ to rt; (f) $\mathrm{MsCl}_{1} \mathrm{Et} 3 \mathrm{~N}, \mathrm{DCM}, 0{ }^{\circ} \mathrm{C}$ to rt; (g) tert-BuOK, THF, rt, $43 \%$ for 3 steps; (h) SFC, ChromegaChiral CC4 column; (i) $\left(\mathrm{CF}_{3} \mathrm{CO}\right)_{2} \mathrm{O}$, pyridine, DCM, $0{ }^{\circ} \mathrm{C}$ to rt, $98 \%$; (j) $\mathrm{H}_{2}$, $\mathrm{Pd}-\mathrm{C}, \mathrm{MeOH} / \mathrm{EtOAc}$, rt, $100 \%$; (k) $\mathrm{POBr}_{3}$, $\mathrm{MeCN}$, anisole, $90{ }^{\circ} \mathrm{C}, 59 \%$; (m) activated $\mathrm{Cu}, \mathrm{IC}\left(\mathrm{CF}_{3}\right)_{2} \mathrm{~F}, \mathrm{DMF}, 120{ }^{\circ} \mathrm{C}$; (n) $\mathrm{LiOH}, \mathrm{THF} / \mathrm{H}_{2} \mathrm{O}$, $85{ }^{\circ} \mathrm{C}, 89 \%$ for 2 steps; (p) RCOOH, HATU, $i-\mathrm{PrNEt}_{2}$, DMF, $71-83 \%$.

\section{3-(Benzyloxy)-5,6-dihydroisoquinolin-8-yl trifluoromethanesulfonate (25).}

A mixture of $24(1.01 \mathrm{~g}, 6.19 \mathrm{mmol}), \mathrm{Ag}_{2} \mathrm{CO}_{3}(1.88 \mathrm{~g}, 6.81 \mathrm{mmol})$ and benzyl bromide $(1.33 \mathrm{~mL}, 11.1 \mathrm{mmol})$ in toluene $(25 \mathrm{~mL})$ was stirred at $\mathrm{rt}$ for 3 days. The mixture was filtered and the solids were washed with EtOAc. The combined filtrates were concentrated and the residue was purified by column chromatography on silica gel $(40 \mathrm{~g})$, eluting with EtOAchexanes (gradient from 5-20\%) to provide 3-benzyloxy-6,7-dihydroisoquinolin-8(5H)-one as a white solid (1.40 g, 89\% yield). HPLC $t_{\mathrm{R}} 1.01 \mathrm{~min}$ (method A). LCMS $\mathrm{m} / z$ calcd for $\mathrm{C}_{16} \mathrm{H}_{16} \mathrm{NO}_{2}$ $[\mathrm{M}+\mathrm{H}]^{+}$254.1, obsd 254.1. ${ }^{1} \mathrm{H}$ NMR $\left(400 \mathrm{MHz}, \mathrm{CDCl}_{3}\right) \delta 8.86(\mathrm{~s}, 1 \mathrm{H}), 7.48-7.43(\mathrm{~m}, 2 \mathrm{H}), 7.41$ - $7.31(\mathrm{~m}, 3 \mathrm{H}), 6.63(\mathrm{~d}, \mathrm{~J}=0.4 \mathrm{~Hz}, 1 \mathrm{H}), 5.46(\mathrm{~s}, 2 \mathrm{H}), 2.89(\mathrm{t}, \mathrm{J}=6.2 \mathrm{~Hz}, 2 \mathrm{H}), 2.68$ - $2.61(\mathrm{~m}, 2 \mathrm{H})$, 2.12 (quin, $\mathrm{J}=6.4 \mathrm{~Hz}, 2 \mathrm{H}$ ).

A solution of this material $(1.40 \mathrm{~g}, 5.53 \mathrm{mmol})$ and $N, N$-bis(trifluoromethylsulfonyl)aniline $(2.57 \mathrm{~g}, 7.19 \mathrm{mmol})$ in THF $(30 \mathrm{ml})$ was cooled to $-78^{\circ} \mathrm{C}$ and treated dropwise with $1 \mathrm{M}$ potassium bis(trimethylsilyl)amide $(7.46 \mathrm{~mL}, 7.46 \mathrm{mmol})$. After $40 \mathrm{~min}$ the mixture was treated with water and warmed to rt. Saturated aq $\mathrm{NaHCO}_{3}$ was added and the mixture was extracted with ether. The organic phase was washed with brine, dried over $\mathrm{Na}_{2} \mathrm{SO}_{4}$ and concentrated. The residue was purified by column chromatography on silica gel ( $40 \mathrm{~g})$, eluting with EtOAc/hexanes (gradient from 0-5\%) to provide 25 as a pale yellow oil (2.11 g, 99\%). HPLC $t_{\mathrm{R}} 1.19 \mathrm{~min}$ (method A). LCMS $m / z$ calcd for $\mathrm{C}_{17} \mathrm{H}_{15} \mathrm{~F}_{3} \mathrm{NO}_{4} \mathrm{~S}[\mathrm{M}+\mathrm{H}]^{+}$386.1, obsd 386.0.

\section{3-(Benzyloxy)-8-((4-fluorophenyl)sulfonyl)-5,6-dihydroisoquinoline (26).}

The compound was synthesized from $\mathbf{2 5}$ according to the procedures used to convert $\mathbf{1 0}$ to 11. HPLC $t_{\mathrm{R}} 1.07 \mathrm{~min}$ (method A). LCMS m/z calcd for $\mathrm{C}_{22} \mathrm{H}_{19} \mathrm{FNO}_{3} \mathrm{~S}[\mathrm{M}+\mathrm{H}]^{+} 396.1$, obsd 396.0 . 
(6aR,9aR)-3-(Benzyloxy)-9a-((4-fluorophenyl)sulfonyl)-6,6a,7,8,9,9a-hexahydro-5Hpyrrolo[2,3- $h$ ]isoquinoline (27).

The compound was synthesized from $\mathbf{2 6}$ according to the procedures used to convert $\mathbf{1 1}$ to 21. HPLC $t_{\mathrm{R}} 0.80 \mathrm{~min}$ (method A). LCMS $m / z$ calcd for $\mathrm{C}_{24} \mathrm{H}_{24} \mathrm{FN}_{2} \mathrm{O}_{3} \mathrm{~S}[\mathrm{M}+\mathrm{H}]^{+} 439.1$, obsd 439.1.

1-((6aR,9aR)-3-Bromo-9a-((4-fluorophenyl)sulfonyl)-5,6,6a,8,9,9a-hexahydro-7Hpyrrolo[2,3-h]isoquinolin-7-yl)-2,2,2-trifluoroethan-1-one (28).

The compound was synthesized from $\mathbf{2 7}$ according to the procedures used to convert $\mathbf{2 1}$ to 22. HPLC $t_{\mathrm{R}} 0.97 \mathrm{~min}$ (method A). LCMS $m / z$ calcd for $\mathrm{C}_{19} \mathrm{H}_{16} \mathrm{BrF}_{4} \mathrm{~N}_{2} \mathrm{O}_{3} \mathrm{~S}[\mathrm{M}+\mathrm{H}]^{+}$507.0, 509.0; obsd 506.9, 508.9.

(6aR,9aR)-9a-((4-Fluorophenyl)sulfonyl)-3-(perfluoropropan-2-yl)-6,6a,7,8,9,9a-hexahydro$5 H$-pyrrolo[2,3- $h]$ isoquinoline (29).

The compound was synthesized from $\mathbf{2 8}$ according to the procedures used to convert $\mathbf{2 2}$ to 23. HPLC $t_{\mathrm{R}} 0.83 \mathrm{~min}$ (method A). LCMS $m / z$ calcd for $\mathrm{C}_{20} \mathrm{H}_{17} \mathrm{~F}_{8} \mathrm{~N}_{2} \mathrm{O}_{2} \mathrm{~S}[\mathrm{M}+\mathrm{H}]^{+}$501.1, obsd 501.1 .

(1,1-Dioxidotetrahydro-2H-thiopyran-4-yl)((6aR,9aR)-9a-((4-fluorophenyl)sulfonyl)-3(perfluoropropan-2-yl)-5,6,6a,8,9,9a-hexahydro-7H-pyrrolo[2,3- $h$ ]isoquinolin-7yl)methanone (6a).

The compound was synthesized from $\mathbf{2 9}$ and tetrahydro- $2 H$-thiopyran-4-carboxylic acid 1,1-dioxide according to the procedures used to synthesize 8a and purified using HPLC method H. HPLC $t_{\mathrm{R}} 2.01 \mathrm{~min}, 100 \%$ (method B), $1.97 \mathrm{~min}, 100 \%$ (method C). LCMS $\mathrm{m} / \mathrm{z}$ calcd for $\mathrm{C}_{26} \mathrm{H}_{25} \mathrm{~F}_{8} \mathrm{~N}_{2} \mathrm{O}_{5} \mathrm{~S}_{2}[\mathrm{M}+\mathrm{H}]^{+} 661.1$; obsd 661.3. High resolution MS (ESI) $\mathrm{m} / z$ calcd for $\mathrm{C}_{26} \mathrm{H}_{25} \mathrm{~F}_{8} \mathrm{~N}_{2} \mathrm{O}_{5} \mathrm{~S}_{2}[\mathrm{M}+\mathrm{H}]^{+}$661.1072; obsd: 661.1089 (+2.58 ppm). ${ }^{1} \mathrm{H}$ NMR $(500 \mathrm{MHz}$, DMSO$\left.\mathrm{d}_{6}\right) \delta 8.92-8.73(\mathrm{~m}, 1 \mathrm{H}), 7.65(\mathrm{br} \mathrm{s}, 1 \mathrm{H}), 7.42$ (br dd, J=8.5, 5.2 Hz, 2H), 7.31 (br t, J=8.7 Hz, $2 \mathrm{H}), 4.80$ - $4.62(\mathrm{~m}, 1 \mathrm{H}), 3.86-3.66(\mathrm{~m}, 2 \mathrm{H}), 3.53-3.28(\mathrm{~m}, 1 \mathrm{H}), 3.24-3.05(\mathrm{~m}, 2 \mathrm{H}), 2.87$ $2.64(\mathrm{~m}, 3 \mathrm{H}), 2.40-1.93(\mathrm{~m}, 7 \mathrm{H}), 1.61-1.27(\mathrm{~m}, 1 \mathrm{H})$. One proton was missing, presumably obscured by water suppression. ${ }^{13} \mathrm{C}$ NMR $\left(151 \mathrm{MHz}\right.$, DMSO- $\left.d_{6}\right) \delta \mathrm{ppm} 25.09$ (s, $\left.1 \mathrm{C}\right) 26.70$ (s, 1 C) 27.05 (s, 1 C) 27.37 (s, 1 C) 33.09 (s, 1 C) 37.94 (s, 1 C) 45.23 (s, 1 C) 49.95 (s, 1 C) 50.00 (s, 1 C) 59.13 (s, 1 C) 73.34 (s, 1 C) 88.18 - 93.24 (m, 1 C) 117.16 (br d, J=23.11 Hz, 2 C) 118.26 - 123.95 (m, 2 C) 121.47 (br d, $J=8.80 \mathrm{~Hz}, 1 \mathrm{C}) 131.43$ (d, $J=2.20 \mathrm{~Hz}, 1 \mathrm{C}) 131.98$ (s, 1 C) $133.16(\mathrm{br} \mathrm{d}, J=9.90 \mathrm{~Hz}, 2 \mathrm{C}) 145.26(\mathrm{~d}, J=25.31 \mathrm{~Hz}, 1 \mathrm{C}) 151.13$ (d, $J=2.20 \mathrm{~Hz}, 1 \mathrm{C}) 151.61$ (s, 1 C) 165.98 (d, J=255.29 Hz, 1 C) 172.40 (s, 1 C).

3-((S)-2-((6aR,9aR)-9a-((4-Fluorophenyl)sulfonyl)-3-(perfluoropropan-2-yl)-6,6a,7,8,9,9ahexahydro-5H-pyrrolo[2,3- $h$ ] isoquinoline-7-carbonyl)-5-oxopyrrolidin-1-yl)propanenitrile (6b).

The compound was synthesized from 29 and (S)-1-(2-cyanoethyl)-5-oxopyrrolidine-2carboxylic acid ${ }^{2}$ according to the procedures used to synthesize 8a, and purified using HPLC method K. HPLC $t_{\mathrm{R}} 9.11 \mathrm{~min}, 94.5 \%$ (method D), $8.60 \mathrm{~min}, 96.2 \%$ (method E). LCMS $\mathrm{m} / z$ calcd for $\mathrm{C}_{28} \mathrm{H}_{25} \mathrm{~F}_{8} \mathrm{~N}_{4} \mathrm{O}_{4} \mathrm{~S}[\mathrm{M}+\mathrm{H}]^{+}$665.1; obsd 665.2. ${ }^{1} \mathrm{H}$ NMR (499 MHz, MeOH-d 4$) \delta 9.00(\mathrm{~s}, 1 \mathrm{H})$, 
$7.52(\mathrm{~d}, \mathrm{~J}=2.6 \mathrm{~Hz}, 1 \mathrm{H}), 7.48-7.39(\mathrm{~m}, 2 \mathrm{H}), 7.18(\mathrm{t}, \mathrm{J}=8.7 \mathrm{~Hz}, 2 \mathrm{H}), 4.95(\mathrm{dd}, \mathrm{J}=12.0,5.0 \mathrm{~Hz}$, $1 \mathrm{H}), 4.83(\mathrm{dd}, \mathrm{J}=8.4,3.2 \mathrm{~Hz}, 1 \mathrm{H}), 4.13(\mathrm{q}, \mathrm{J}=8.9 \mathrm{~Hz}, 1 \mathrm{H}), 3.92-3.83(\mathrm{~m}, 2 \mathrm{H}), 3.68$ (ddd, J=14.7, 8.1, 3.0 Hz, 1H), $2.90-2.69(\mathrm{~m}, 4 \mathrm{H}), 2.57-2.41(\mathrm{~m}, 4 \mathrm{H}), 2.14-2.00(\mathrm{~m}, 2 \mathrm{H}), 1.43(\mathrm{qd}, \mathrm{J}=12.7$, $3.2 \mathrm{~Hz}, 1 \mathrm{H})$.

\section{Scheme S5. Synthesis of compounds 7a-b}

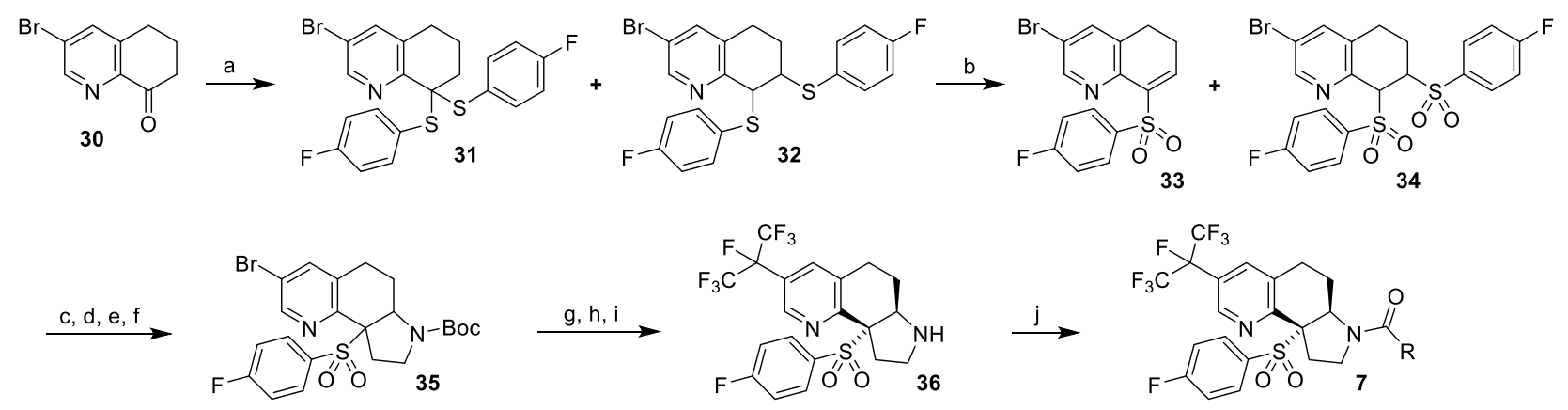

${ }^{a}$ Reagents and conditions: (a) 4-fluorobenzenethiol, $\mathrm{HCl}$ gas, $i$ - $\mathrm{PrOH}, 0{ }^{\circ} \mathrm{C}$ to $\mathrm{rt} \mathrm{(1:3);} \mathrm{(b)}$ mCPBA, DCM, $0{ }^{\circ} \mathrm{C}$ to $\mathrm{rt}$; (c) ethanolamine, THF, $0{ }^{\circ} \mathrm{C}$ to $\mathrm{rt}$; (d) $\mathrm{MsCl}, \mathrm{Et}_{3} \mathrm{~N}, \mathrm{DCM}, 0{ }^{\circ} \mathrm{C}$ to $\mathrm{rt}$; (e) tert-BuOK, THF, rt; (f) (Boc) $)_{2} \mathrm{O}, \mathrm{Et}_{3} \mathrm{~N}, \mathrm{DCM}, \mathrm{rt}, 12 \%$ overall; $(\mathrm{g})$ activated $\mathrm{Cu}, \mathrm{IC}\left(\mathrm{CF}_{3}\right)_{2} \mathrm{~F}$, DMF, $120^{\circ} \mathrm{C}$; (h) SFC; (R,R)Whelk-O1 column (i) TFA, DCM, 77\% for 3 steps; (j) RCOOH, HATU, $i$-PrNEt 2 , DMF, 55-87\%.

tert-Butyl 3-bromo-9a-((4-fluorophenyl)sulfonyl)-5,6,6a,8,9,9a-hexahydro-7H-pyrrolo[2,3h]quinoline-7-carboxylate (35).

A suspension of 3-bromo-6,7-dihydroquinolin-8(5H)-one $(\mathbf{3 0}, 5.58 \mathrm{~g}, 24.7 \mathrm{mmol})$ in $i$ $\mathrm{PrOH}(50 \mathrm{~mL})$ was treated with 4-fluorobenzenethiol $(6.10 \mathrm{~mL}, 56.8 \mathrm{mmol})$. The mixture was cooled to $0{ }^{\circ} \mathrm{C}$ and bubbled with $\mathrm{HCl}$ gas for $\sim 5 \mathrm{~min}$, and the mixture stirred overnight at rt. After $17 \mathrm{~h}$, significant starting material remained by LCMS, so additional $i$-PrOH $(50 \mathrm{~mL})$ was added and the mixture was again bubbled with $\mathrm{HCl}$ gas for $10 \mathrm{~min}$. After $3 \mathrm{~h}$ more, the mixture was poured into an ice-water mixture, EtOAc was added, and $\mathrm{NaHCO}_{3}$ was slowly added with stirring until gas evolution ceased. The organic phase was separated, washed with saturated aq $\mathrm{NaHCO}_{3}$ and brine, dried and concentrated. The residue was subjected to column chromatography on silica gel $(120 \mathrm{~g})$, eluting with EtOAc-hexanes, to provide a 1:3 mixture of 31 and 3-bromo-7,8-bis((4-fluorophenyl)thio)-5,6,7,8-tetrahydroquinoline (32) as a light yellow $\operatorname{syrup}(3.67 \mathrm{~g})$, used without further purification. HPLC $t_{\mathrm{R}} 1.24 \mathrm{~min}$ (method A). LCMS $\mathrm{m} / \mathrm{z}$ calcd for $\mathrm{C}_{21} \mathrm{H}_{17} \mathrm{BrF}_{2} \mathrm{NS}_{2}[\mathrm{M}+\mathrm{H}]^{+}$464.0, 466.0; obsd 463.9, 465.9.

A solution of this mixture $(3.45 \mathrm{~g}, 7.43 \mathrm{mmol})$ in DCM $(120 \mathrm{~mL})$ was treated at $0{ }^{\circ} \mathrm{C}$ with a solution of mCPBA $(8.32 \mathrm{~g}, 37.1 \mathrm{mmol})$ in DCM $(80 \mathrm{~mL})$. The mixture was warmed to $\mathrm{rt}$ and stirred for $1.5 \mathrm{~h}$, then was washed with saturated aq $\mathrm{NaHCO}_{3}$, aq $\mathrm{NaS}_{2} \mathrm{O}_{3}$ and brine, dried and concentrated to give a 1:3 mixture of $\mathbf{3 3}$ and 3-bromo-7,8-bis((4-fluorophenyl)sulfonyl)5,6,7,8-tetrahydroquinoline (34) as a white glassy solid (3.92 g), used without further purification. HPLC $t_{\mathrm{R}} 0.97(\mathbf{3 3})$ and $1.00 \mathrm{~min}(\mathbf{3 4})$ (method A). LCMS $\mathrm{m} / z$ calcd for 
$\mathrm{C}_{15} \mathrm{H}_{12} \mathrm{BrFNO}_{2} \mathrm{~S}[\mathrm{M}+\mathrm{H}]^{+}$368.0, 370.0; obsd 367.9, $369.9(\mathbf{3 3})$; calcd for $\mathrm{C}_{21} \mathrm{H}_{17} \mathrm{BrF}_{2} \mathrm{NO}_{4} \mathrm{~S}_{2}$ $[\mathrm{M}+\mathrm{H}]^{+}$528.0, 530.0; obsd 527.9, $529.9(\mathbf{3 4})$.

A solution of this mixture $(3.92 \mathrm{~g})$ in THF $(74 \mathrm{~mL})$ was stirred at $0{ }^{\circ} \mathrm{C}$ and treated with ethanolamine $(1.8 \mathrm{~mL}, 29.7 \mathrm{mmol})$. The mixture was warmed to $\mathrm{rt}$, stirred for $1 \mathrm{~h}$, and partitioned between EtOAc and saturated aq $\mathrm{NaHCO}_{3}$. The organic phase was washed with brine, dried and concentrated to afford crude 2-((3-bromo-8-((4-fluorophenyl)sulfonyl)-5,6,7,8tetrahydroquinolin-7-yl)amino)ethanol as a yellow glassy foam (3.19 g), used without further purification. HPLC $t_{\mathrm{R}} 0.67 \mathrm{~min}$ (method A). LCMS m/z calcd for $\mathrm{C}_{17} \mathrm{H}_{19} \mathrm{BrFN}_{2} \mathrm{O}_{3} \mathrm{~S}[\mathrm{M}+\mathrm{H}]^{+}$ 429.0, 431.0; obsd 428.9, 430.9.

A solution of this material $(3.19 \mathrm{~g})$ in DCM $(200 \mathrm{~mL})$ was stirred at $0{ }^{\circ} \mathrm{C}$ and treated with methanesulfonyl chloride $(0.533 \mathrm{~mL}, 6.84 \mathrm{mmol})$ and $\mathrm{Et}_{3} \mathrm{~N}(0.953 \mathrm{~mL}, 6.84 \mathrm{mmol})$. The mixture was warmed to rt and stirred for $1 \mathrm{~h}$. A solution of potassium tert-butoxide $(3.34 \mathrm{~g}, 29.7 \mathrm{mmol})$ in THF $(40 \mathrm{~mL})$ was added slowly and stirring was continued for $1 \mathrm{~h}$. The mixture was partitioned between DCM and aq $\mathrm{NaHCO}_{3}$. The organic phase was washed with brine, dried and concentrated to afford crude racemic 3-bromo-9a-((4-fluorophenyl)sulfonyl)-6,6a,7,8,9,9ahexahydro-5H-pyrrolo[2,3- $h$ ]quinoline as a light brown glassy solid $(2.73 \mathrm{~g})$, used without further purification. For characterization, a small amount was purified by column chromatography on silica gel, eluting with EtOAc-hexanes (gradient from 50-100\%). HPLC $t_{\mathrm{R}}$ 0.68 min (method A). LCMS m/z calcd for $\mathrm{C}_{17} \mathrm{H}_{17} \mathrm{BrFN}_{2} \mathrm{O}_{2} \mathrm{~S}[\mathrm{M}+\mathrm{H}]^{+}$411.0, 413.0; obsd 411.0, 413.0. ${ }^{1} \mathrm{H}$ NMR $\left(400 \mathrm{MHz}, \mathrm{CDCl}_{3}\right) \delta 8.32(\mathrm{~d}, \mathrm{~J}=1.5 \mathrm{~Hz}, 1 \mathrm{H}), 7.60(\mathrm{~d}, \mathrm{~J}=2.0 \mathrm{~Hz}, 1 \mathrm{H}), 7.45$ - 7.38 (m, 2H), $7.10(\mathrm{t}, \mathrm{J}=8.6 \mathrm{~Hz}, 2 \mathrm{H}), 4.50$ (dd, J=11.0, 6.2 Hz, 1H), 3.28 (ddd, J=11.7, 7.2, 4.6 Hz, $1 \mathrm{H}), 2.97-2.56(\mathrm{~m}, 5 \mathrm{H}), 2.42-2.31(\mathrm{~m}, 1 \mathrm{H}), 1.41(\mathrm{tdd}, \mathrm{J}=12.8,11.1,3.9 \mathrm{~Hz}, 1 \mathrm{H})$. One exchangeable $\mathrm{NH}$ proton is missing from the NMR.

A solution of the crude material $(2.73 \mathrm{~g})$ in DCM $(43 \mathrm{~mL})$ was treated with a solution of di-tert-butyl dicarbonate $(1.34 \mathrm{~mL}, 5.78 \mathrm{mmol})$ in DCM $(4.8 \mathrm{~mL})$ and $\mathrm{Et}_{3} \mathrm{~N}(1.34 \mathrm{~mL}, 9.63$ $\mathrm{mmol})$. The mixture was stirred at $\mathrm{rt}$ for $2 \mathrm{~h}$, then was partitioned between DCM and saturated aq $\mathrm{NaHCO}_{3}$. The organic phase was dried and concentrated, and the residue was subjected to column chromatography on silica gel (80 g), eluting with EtOAc-hexanes (gradient from 10$20 \%$ ), to provide 35 as a white glassy solid ( $1.18 \mathrm{~g}, 12 \%$ overall yield). HPLC $t_{\mathrm{R}} 1.08 \mathrm{~min}$ (method A). LCMS $m / z$ calcd for $\mathrm{C}_{22} \mathrm{H}_{25} \mathrm{BrFN}_{2} \mathrm{O}_{4} \mathrm{~S}[\mathrm{M}+\mathrm{H}]^{+}$511.0, 513.0; obsd 510.9, 512.9 .

\section{(6aR,9aS)-9a-((4-Fluorophenyl)sulfonyl)-3-(perfluoropropan-2-yl)-6,6a,7,8,9,9a-hexahydro- $5 H$-pyrrolo[2,3- $h]$ quinoline hydrochloride (36).}

A mixture of dried activated copper (1.68 g, $26.4 \mathrm{mmol}), 35$ (0.900 g, $1.76 \mathrm{mmol})$, DMF $(12 \mathrm{~mL})$, and perfluoro-2-iodopropane $(1.13 \mathrm{~mL}, 7.92 \mathrm{mmol})$ was sealed under nitrogen in a pressure vial and stirred at $120^{\circ} \mathrm{C}$ for $3 \mathrm{~h}$. The mixture was cooled to rt, filtered through Celite, and the solids were washed with EtOAc. The combined filtrates were washed with saturated aq $\mathrm{NaHCO}_{3}, 10 \%$ aq LiCl and brine, dried and concentrated to provide racemic tert-butyl 9a-((4fluorophenyl)sulfonyl)-3-(perfluoropropan-2-yl)-6,6a,9,9a-tetrahydro-5H-pyrrolo[2,3$h$ ]quinoline- $7(8 H)$-carboxylate as a brown syrup $(1.63 \mathrm{~g})$. HPLC $t_{\mathrm{R}} 1.17 \mathrm{~min}$ (method A). LCMS $m / z$ calcd for $\mathrm{C}_{25} \mathrm{H}_{25} \mathrm{~F}_{8} \mathrm{~N}_{2} \mathrm{O}_{4} \mathrm{~S}[\mathrm{M}+\mathrm{H}]^{+} 601.1$; obsd 601.1.

A sample of this crude material (2.36 g,) was separated into its enantiomers by preparative SFC using the following conditions: Column, (R,R)Whelk-O1 $(5 \times 50 \mathrm{~cm}, 10 \mu)$; temperature $35^{\circ} \mathrm{C}$; mobile phase: $\mathrm{CO}_{2} / i-\mathrm{PrOH}(90: 10)$ with $0.1 \% \mathrm{NH}_{4} \mathrm{OH}$; flow rate 300 $\mathrm{mL} / \mathrm{min}$; pressure $100 \mathrm{bar} ; 0.8 \mathrm{~mL}$ injections. The first-eluted peaks from all injections were combined and concentrated to provide a yellow solid. This was dissolved in DCM (13 mL) and 
THF $(4 \mathrm{~mL})$ and treated with TFA $(0.984 \mathrm{~mL})$. After $6 \mathrm{~h}$, the mixture was partitioned between DCM and a mixture of $1.5 \mathrm{M}^{2} \mathrm{~K}_{2} \mathrm{HPO}_{4}$ and $1 \mathrm{M}$ aq $\mathrm{NaOH}$. The organic phase was washed with brine, dried and concentrated. The residue was dissolved in DCM, treated with $\mathrm{HCl}$ (4 M in dioxane), and the solution was concentrated to provide $\mathbf{3 6}$ as a light yellow solid $(0.49 \mathrm{~g}, 77 \%$ yield overall). HPLC $t_{\mathrm{R}} 0.84 \mathrm{~min}(\operatorname{method} \mathrm{A})$. LCMS $\mathrm{m} / \mathrm{z}$ calcd for $\mathrm{C}_{20} \mathrm{H}_{17} \mathrm{~F}_{8} \mathrm{~N}_{2} \mathrm{O}_{2} \mathrm{~S}[\mathrm{M}+\mathrm{H}]^{+}$ 501.1; obsd 501.1. ${ }^{1} \mathrm{H}$ NMR (499 MHz, DMSO-d $) \delta 10.10-9.57(\mathrm{~m}, 2 \mathrm{H}), 8.53(\mathrm{~d}, \mathrm{~J}=1.7 \mathrm{~Hz}$, 1H), 8.08 (s, 1H), $7.44-7.38$ (m, 2H), 7.35 - 7.29 (m, 2H), 4.85 (dd, J=11.0, $6.8 \mathrm{~Hz}, 1 \mathrm{H}), 3.46$ (dd, J=8.4, 5.6 Hz, 2H), 3.13 - 2.97 (m, 2H), 2.82 (dt, J=14.9, 8.5 Hz, 1H), 2.75 - 2.63 (m, 1H), $2.58-2.53(\mathrm{~m}, 1 \mathrm{H}), 1.87-1.75(\mathrm{~m}, 1 \mathrm{H})$. The integration includes one $\mathrm{HCl}$ proton.

The second-eluted peaks were combined and concentrated, and the residue was deprotected as above, to provide $(6 \mathrm{a} S, 9 \mathrm{a} R)-9 \mathrm{a}-((4-$ fluorophenyl)sulfonyl)-3-(perfluoropropan-2yl)-6,6a,7,8,9,9a-hexahydro-5H-pyrrolo[2,3- $h$ ]quinoline hydrochloride. HPLC, LCMS and NMR identical to those of $\mathbf{3 6}$.

The absolute configurations were assumed based on the lack of biological activity of final compounds derived from the second-eluting material.

\section{(1,1-Dioxidotetrahydro-2H-thiopyran-4-yl)((6aR,9aS)-9a-((4-fluorophenyl)sulfonyl)-3- (perfluoropropan-2-yl)-6,6a,9,9a-tetrahydro-5H-pyrrolo[2,3- $h]$ quinolin-7(8H)- yl)methanone (7a).}

The compound was synthesized in $87 \%$ yield from 36 and tetrahydro- $2 H$-thiopyran-4carboxylic acid 1,1-dioxide according to the procedures used to synthesize 8a, following purification using HPLC method J. HPLC $t_{\mathrm{R}} 1.92 \mathrm{~min}, 100 \%$ (method B), $1.90 \mathrm{~min}, 100 \%$ (method C). LCMS $m / z$ calcd for $\mathrm{C}_{26} \mathrm{H}_{25} \mathrm{~F}_{8} \mathrm{~N}_{2} \mathrm{O}_{5} \mathrm{~S}_{2}[\mathrm{M}+\mathrm{H}]^{+} 661.1$; obsd 660.8. High resolution MS (ESI) $m / z$ calcd for $\mathrm{C}_{26} \mathrm{H}_{25} \mathrm{~F}_{8} \mathrm{~N}_{2} \mathrm{O}_{5} \mathrm{~S}_{2}[\mathrm{M}+\mathrm{H}]^{+} 661.1072$; obsd: 661.1084 (+1.82 ppm). ${ }^{1} \mathrm{H}$ NMR (500 MHz, DMSO-d 6 ) $\delta 8.62$ (br. s., 1H), 7.93 (br. s., 1H), 7.55 - 7.43 (m, 2H), 7.35 $7.24(\mathrm{~m}, 2 \mathrm{H}), 4.96$ (dd, J=11.1, $4.4 \mathrm{~Hz}, 1 \mathrm{H}), 3.90$ - $3.63(\mathrm{~m}, 2 \mathrm{H}), 3.41$ - $3.04(\mathrm{~m}, 6 \mathrm{H}), 2.91$ - 2.66 (m, 3H), $2.47-2.38(\mathrm{~m}, 1 \mathrm{H}), 2.36-2.13(\mathrm{~m}, 1 \mathrm{H}), 2.10-1.94(\mathrm{~m}, 3 \mathrm{H}), 1.67-1.32(\mathrm{~m}, 1 \mathrm{H}) .{ }^{13} \mathrm{C}$ NMR (151 MHz, DMSO-d6) $\delta$ ppm 25.90 (s, 1 C) 26.08 (s, 1 C) 26.75 (s, 1 C) 27.38 (s, 1 C) $33.34(\mathrm{~s}, 1 \mathrm{C}) 38.07(\mathrm{~s}, 1 \mathrm{C}) 45.01(\mathrm{~s}, 1 \mathrm{C}) 49.99-50.03(\mathrm{~m}, 1 \mathrm{C}) 50.05$ (s, 1 C) 58.87 (s, $1 \mathrm{C})$ 76.83 (s, 1 C) 89.60 - $92.11(\mathrm{~m}, 1 \mathrm{C}) 116.63(\mathrm{~d}, J=22.89 \mathrm{~Hz}, 2 \mathrm{C}) 117.16-123.63$ (m, $2 \mathrm{C})$ 121.52 (d, J=20.71 Hz, 1 C) 132.50 (d, J=3.27 Hz, 1 C) 133.24 (d, J=9.81 Hz, 2 C) 134.22 (d, $J=9.81 \mathrm{~Hz}, 1 \mathrm{C}) 136.73(\mathrm{~d}, J=2.18 \mathrm{~Hz}, 1 \mathrm{C}) 143.98$ (d, J=8.72 Hz, 1 C) 155.79 (s, $1 \mathrm{C}) 165.87$ (d, $J=253.95 \mathrm{~Hz}, 1 \mathrm{C}) 172.28(\mathrm{~s}, 1 \mathrm{C})$.

\section{3-((S)-2-((6aR,9aS)-9a-((4-Fluorophenyl)sulfonyl)-3-(perfluoropropan-2-yl)-6,6a,7,8,9,9a-} hexahydro-5H-pyrrolo[2,3- $h$ ]quinoline-7-carbonyl)-5-oxopyrrolidin-1-yl)propanenitrile (7b).

The compound was synthesized in 55\% yield from 36 and (S)-1-(2-cyanoethyl)-5oxopyrrolidine-2-carboxylic acid ${ }^{2}$ according to the procedures used to synthesize 8a following purification using HPLC method J. HPLC $t_{\mathrm{R}} 1.94 \mathrm{~min}, 97.8 \%(\operatorname{method} \mathrm{B}), 1.88 \mathrm{~min}, 99.0 \%$ (method C). LCMS $m / z$ calcd for $\mathrm{C}_{28} \mathrm{H}_{25} \mathrm{~F}_{8} \mathrm{~N}_{4} \mathrm{O}_{4} \mathrm{~S}[\mathrm{M}+\mathrm{H}]^{+} 665.1$; obsd 665.2. High resolution MS (ESI) $m / z$ calcd for $\mathrm{C}_{28} \mathrm{H}_{25} \mathrm{~F}_{8} \mathrm{~N}_{4} \mathrm{O}_{4} \mathrm{~S}[\mathrm{M}+\mathrm{H}]^{+} 665.1463$; obsd: 665.1469 (+0.83 ppm). ${ }^{1} \mathrm{H}$ NMR (500 MHz, DMSO-d 6 ) $\delta 8.65$ (br. s., 1H), 7.95 (br. s., 1H), 7.51 (d, J=4.9 Hz, 2H), 7.38 $7.23(\mathrm{~m}, 2 \mathrm{H}), 5.10$ - $4.63(\mathrm{~m}, 2 \mathrm{H}), 4.05-3.31(\mathrm{~m}, 4 \mathrm{H}), 3.19-2.95(\mathrm{~m}, 2 \mathrm{H}), 2.90$ - $2.67(\mathrm{~m}, 4 \mathrm{H})$, 2.46 (br. s., 1H), 2.35 - 2.16 (m, 3H), $1.94-1.42$ (m, 2H). ${ }^{13} \mathrm{C}$ NMR (151 MHz, DMSO-d $) \delta$ 
ppm $16.12(\mathrm{~s}, 1 \mathrm{C}) 22.97(\mathrm{~s}, 1 \mathrm{C}) 25.47(\mathrm{~s}, 1 \mathrm{C}) 25.92(\mathrm{~s}, 1 \mathrm{C}) 29.24(\mathrm{~s}, 1 \mathrm{C}) 33.71$ (s, $1 \mathrm{C}) 38.01$ (s, 1 C) $44.56(\mathrm{~s}, 1 \mathrm{C}) 58.05(\mathrm{~s}, 1 \mathrm{C}) 59.21(\mathrm{~s}, 1 \mathrm{C}) 76.46(\mathrm{~s}, 1 \mathrm{C}) 89.41$ - 92.27 (m, 1 C) 116.67 (d, $J=22.89 \mathrm{~Hz}, 2 \mathrm{C}) 117.27-123.49$ (m, 2 C) 119.52 (s, 1 C) 121.58 (d, J=20.71 Hz, $1 \mathrm{C}$ ) $132.49(\mathrm{~d}, J=3.27 \mathrm{~Hz}, 1 \mathrm{C}) 133.26(\mathrm{~d}, J=9.81 \mathrm{~Hz}, 2 \mathrm{C}) 134.28(\mathrm{~d}, J=9.81 \mathrm{~Hz}, 1 \mathrm{C}) 136.78(\mathrm{~d}$, $J=2.18 \mathrm{~Hz}, 1 \mathrm{C}) 144.02$ (d, J=8.72 Hz, 1 C) 155.52 (s, 1 C) 165.88 (d, J=255.04 Hz, 1 C) 170.17 (s, 1 C) 175.49 (s, 1 C).

\section{Scheme S6. Synthesis of Compounds 3d-e}
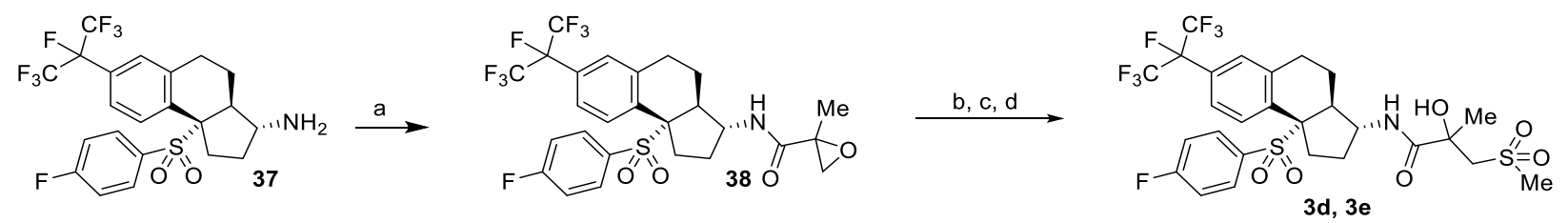

Reagents and conditions: (a) 2-meethylglycidic acid, HATU, $i$-PrNEt 2, DCM, rt, 63\%; (b) NaSMe, HOAc, MeOH, rt; (c) mCPBA, DCM, rt; (d) SFC, Lux Cellulose-4 column, 25-28\%.

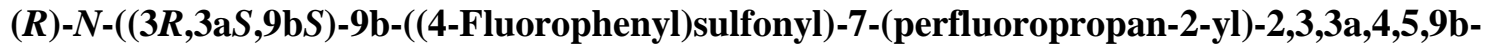
hexahydro-1H-cyclopenta[a]naphthalen-3-yl)-2-hydroxy-2-methyl-3-(methylsulfonyl)propanamide

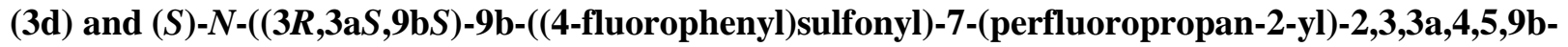
hexahydro-1H-cyclopenta[ $a]$ naphthalen-3-yl)-2-hydroxy-2-methyl-3-(methylsulfonyl)propanamide (3e).

A solution of methyl 2-methylglycidate $(0.082 \mathrm{~mL}, 0.779 \mathrm{mmol})$ in DMF $(0.3 \mathrm{~mL})$ was treated with a solution of $\mathrm{LiOH}$ monohydrate $(32.7 \mathrm{mg}, 0.779 \mathrm{mmol})$ in water $(0.5 \mathrm{~mL})$. The mixture was stirred at $\mathrm{rt}$ for $70 \mathrm{~min}$ and concentrated under vacuum. The residue was combined with pyridinium $\mathrm{p}$ toluenesulfonate (196 mg, $0.779 \mathrm{mmol}$ ), $\mathbf{3 7}^{3}$ (200 mg, $0.390 \mathrm{mmol}$ ), HATU (222 $\mathrm{mg}, 0.584$ $\mathrm{mmol}), i-\mathrm{PrNEt}_{2}(0.136 \mathrm{~mL}, 0.779 \mathrm{mmol})$ and DCM $(3 \mathrm{~mL})$. The mixture was stirred at rt for 60 min and concentrated. The residue was purified by column chromatography on silica gel (4 g), eluting with EtOAc-hexanes (gradient from $0-100 \%)$ to provide $N-((3 R, 3 \mathrm{a} S, 9 \mathrm{~b} S)-9 \mathrm{~b}-((4-$ fluorophenyl)sulfonyl)-7-(perfluoropropan-2-yl)-2,3,3a,4,5,9b-hexahydro- $1 H$ cyclopenta[ $a$ ]naphthalen-3-yl)-2-methyloxirane-2-carboxamide 38 (146 mg, 63\% yield) as a mixture of diastereomers. HPLC $t_{\mathrm{R}} 1.07 \mathrm{~min}$ (method A). LCMS $m / z$ calcd for $\mathrm{C}_{26} \mathrm{H}_{24} \mathrm{~F}_{8} \mathrm{NO}_{4} \mathrm{~S}[\mathrm{M}+\mathrm{H}]^{+}$ 598.1; obsd 598.3.

This material (140 mg, $0.234 \mathrm{mmol})$ and HOAc $(0.013 \mathrm{~mL}, 0.234 \mathrm{mmol})$ were dissolved in $\mathrm{MeOH}(2 \mathrm{~mL})$. Sodium methanethiolate $(65.7 \mathrm{mg}, 0.937 \mathrm{mmol})$ was added and the mixture was stirred at $\mathrm{rt}$ for $20 \mathrm{~min}$. The mixture was concentrated and the residue was partitioned between EtOAc and saturated aq $\mathrm{NaHCO}_{3}$. The aq layer was extracted twice more with EtOAc and the combined organic phases were dried over $\mathrm{Na}_{2} \mathrm{SO}_{4}$ and concentrated. The residue was dissolved in DCM (3 mL) and treated with mCPBA (210 mg, $0.937 \mathrm{mmol})$. The mixture was stirred at $\mathrm{rt}$ for $1 \mathrm{~h}$, then was treated with aq $\mathrm{Na}_{2} \mathrm{~S}_{2} \mathrm{O}_{3}$. The aq layer was separated and extracted with EtOAc. The combined organic phases were washed with saturated aq $\mathrm{NaHCO}_{3}$, dried over $\mathrm{Na}_{2} \mathrm{SO}_{4}$ and concentrated. The residue was purified by column chromatography on silica gel, and this material was separated by SFC using the following conditions: Column, Lux Cellulose-4 (30 x $250 \mathrm{~mm}, 5 \square \mathrm{m}$ ); temperature $40{ }^{\circ} \mathrm{C}$; mobile phase: $\mathrm{CO}_{2} / \mathrm{MeOH}$ (88:12); flow rate 170 $\mathrm{mL} / \mathrm{min}$; pressure $100 \mathrm{bar} ; 1 \mathrm{~mL}$ injections. The first-eluted peaks from all injections were combined and concentrated to provide $3 \mathbf{d}$ (45 mg, 28\% yield). HPLC $t_{\mathrm{R}} 11.46 \mathrm{~min}, 94.9 \%$ 
(method F), 10.54 min, $100 \%$ (method G). LCMS m/z calcd for $\mathrm{C}_{27} \mathrm{H}_{28} \mathrm{~F}_{8} \mathrm{NO}_{6} \mathrm{~S}_{2}[\mathrm{M}+\mathrm{H}]^{+} 678.1$; obsd 678.4. ${ }^{1} \mathrm{H}$ NMR $\left(400 \mathrm{MHz}, \mathrm{CDCl}_{3}\right) \delta 7.86(\mathrm{br} \mathrm{d}, J=8.9 \mathrm{~Hz}, 1 \mathrm{H}), 7.68(\mathrm{~d}, J=8.4 \mathrm{~Hz}, 1 \mathrm{H})$, 7.49 (br d, $J=8.2 \mathrm{~Hz}, 1 \mathrm{H}), 7.24-7.12(\mathrm{~m}, 3 \mathrm{H}), 6.93$ (t, $J=8.5 \mathrm{~Hz}, 2 \mathrm{H}), 4.50$ (br s, $1 \mathrm{H}), 4.38$ - 4.26 $(\mathrm{m}, 1 \mathrm{H}), 3.98(\mathrm{~d}, J=14.7 \mathrm{~Hz}, 1 \mathrm{H}), 3.37-3.24(\mathrm{~m}, 2 \mathrm{H}), 3.07(\mathrm{~s}, 3 \mathrm{H}), 2.86$ (ddd, $J=12.2,5.9,4.0$ $\mathrm{Hz}, 1 \mathrm{H}), 2.49$ (dt, J=15.9, 3.3 Hz, 1H), 2.40 (dt, J=14.6, $7.4 \mathrm{~Hz}, 1 \mathrm{H}), 2.24$ - 2.09 (m, 3H), 1.72 $1.64(\mathrm{~m}, 1 \mathrm{H}), 1.56(\mathrm{~s}, 3 \mathrm{H}), 1.32-1.26(\mathrm{~m}, 1 \mathrm{H})$.

The second-eluted peaks from all injections were combined and concentrated to provide $3 \mathbf{e}\left(40 \mathrm{mg}, 25 \%\right.$ yield). HPLC $t_{\mathrm{R}} 11.35 \mathrm{~min}, 100 \%$ (method $\left.\mathrm{F}\right), 10.47 \mathrm{~min}, 100 \%$ (method G). LCMS $m / z$ calcd for $\mathrm{C}_{27} \mathrm{H}_{28} \mathrm{~F}_{8} \mathrm{NO}_{6} \mathrm{~S}_{2}[\mathrm{M}+\mathrm{H}]^{+}$678.1; obsd 678.4. ${ }^{1} \mathrm{H} \mathrm{NMR}\left(400 \mathrm{MHz}, \mathrm{CDCl}_{3}\right) \delta$ 7.89 (br d, $J=8.5 \mathrm{~Hz}, 1 \mathrm{H}), 7.67$ (d, $J=8.5 \mathrm{~Hz}, 1 \mathrm{H}), 7.50$ (br d, $J=8.4 \mathrm{~Hz}, 1 \mathrm{H}), 7.21-7.14$ (m, 3H), $6.94(\mathrm{t}, J=8.5 \mathrm{~Hz}, 2 \mathrm{H}), 4.60(\mathrm{~s}, 1 \mathrm{H}), 4.35-4.25(\mathrm{~m}, 1 \mathrm{H}), 3.90(\mathrm{~d}, J=15.0 \mathrm{~Hz}, 1 \mathrm{H}), 3.35(\mathrm{~d}$, $J=15.0 \mathrm{~Hz}, 1 \mathrm{H}), 3.31-3.21(\mathrm{~m}, 1 \mathrm{H}), 3.05(\mathrm{~s}, 3 \mathrm{H}), 2.89$ (ddd, $J=12.3,6.0,3.2 \mathrm{~Hz}, 1 \mathrm{H}), 2.55$ $2.40(\mathrm{~m}, 2 \mathrm{H}), 2.18(\mathrm{ddd}, J=13.2,6.3,3.5 \mathrm{~Hz}, 1 \mathrm{H}), 2.14-2.04(\mathrm{~m}, 2 \mathrm{H}), 1.76-1.66(\mathrm{~m}, 1 \mathrm{H}), 1.60$ (s, 3H), $1.33-1.21(\mathrm{~m}, 1 \mathrm{H})$.

The absolute configurations are tentative, and were assigned based on differences in biological activity by analogy with compounds $\mathbf{8 d}$ and $\mathbf{8 e}$. 


\section{Analytical HPLC Report for Compound 8e}

Column 1: Method D; Column 2: MethodE

Overlay Chromatograms of $\mathrm{Col}-1$ and $\mathrm{Col}-2$ at $220 \mathrm{~nm}$

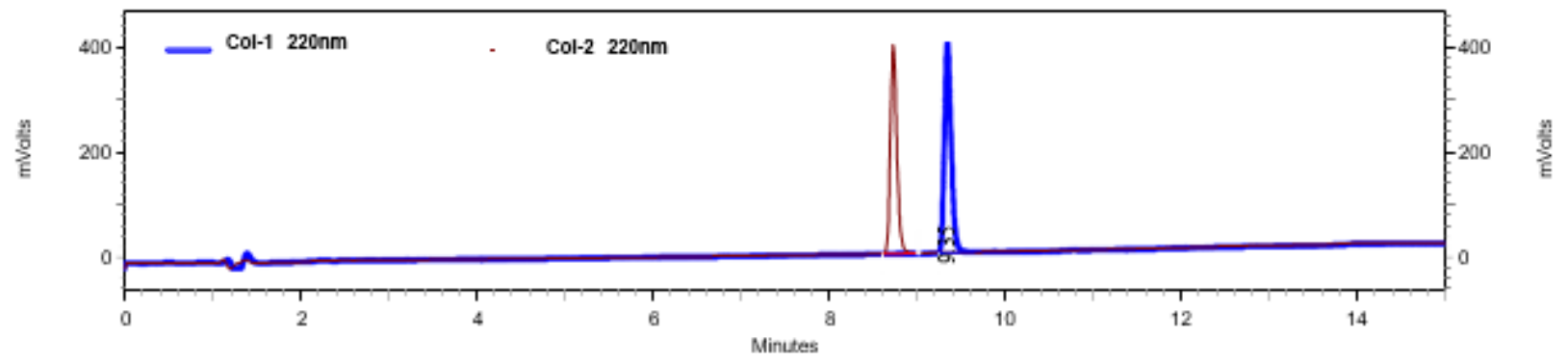

\begin{tabular}{|c|c|c|c|c|}
\hline $\begin{array}{c}\text { Col-1 } 220 \mathrm{~mm} \text { Results } \\
\mathrm{Pl} \#\end{array}$ & Retention Time & Area & Area Percent & Width at 1005 height \\
\hline 1 & 9.351 & 2121467 & 100.0 & 0.156 \\
\hline Totals & & 2121467 & 100.0 & \\
\hline $\begin{array}{c}\text { Col-2 } 220 \mathrm{~mm} \text { Results } \\
\mathrm{Pk} \#\end{array}$ & Retention Time & Area & Area Percent & Width at $100 \mathrm{~s}$ height \\
\hline 1 & 8.726 & 1945570 & 100.0 & 0.151 \\
\hline Totals & & 1945570 & 100.0 & \\
\hline
\end{tabular}




\section{${ }^{1}$ H NMR for compound 8e}

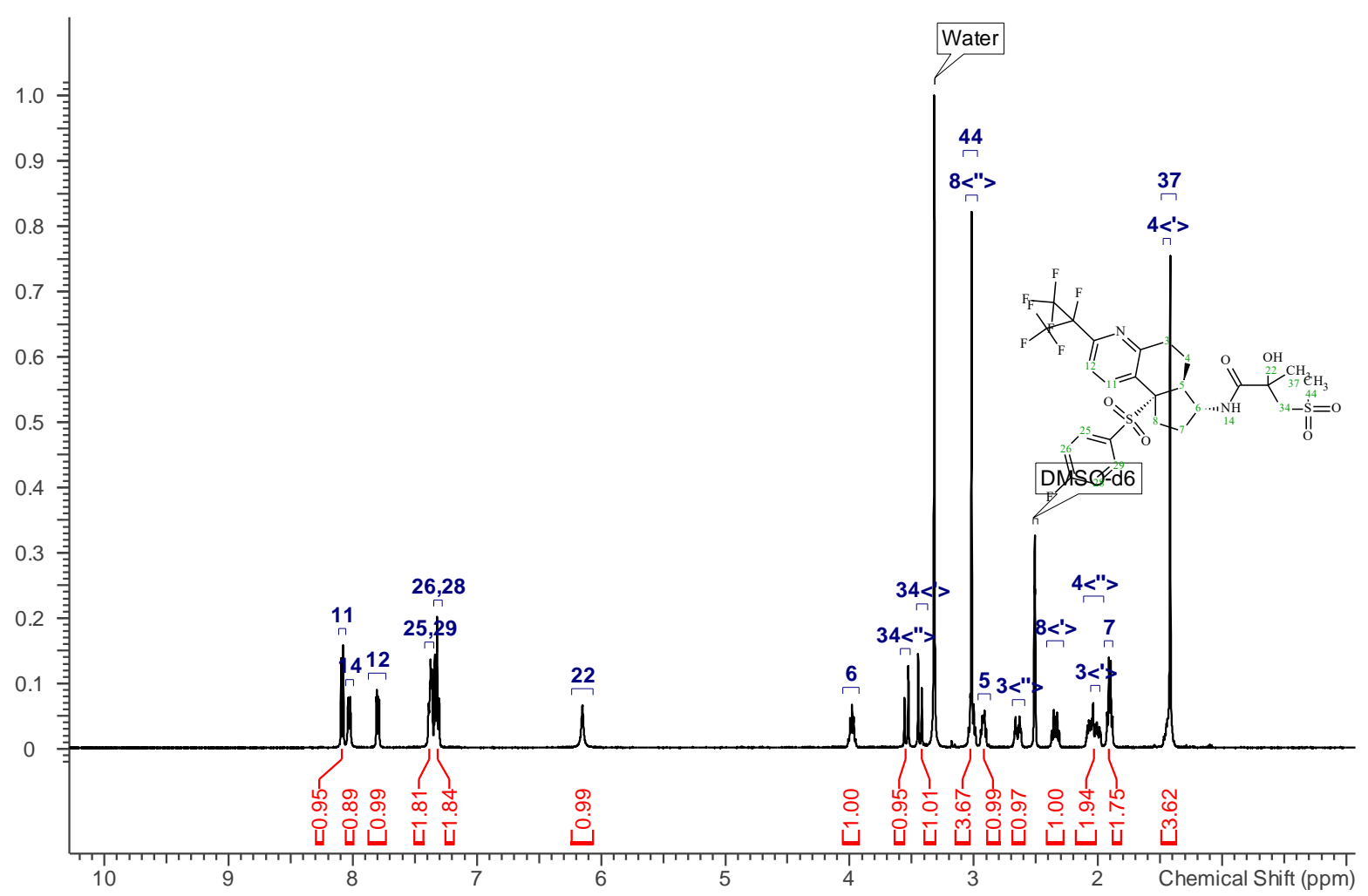

${ }^{1} \mathrm{H}$ NMR (500 MHz, DMSO-d $\left.d_{6}\right) \delta$ ppm 1.42 (s, $\left.3 \mathrm{H}\right) 1.42-1.48$ (m, $\left.1 \mathrm{H}\right) 1.90$ (q, J=7.21 Hz, 2 H) 1.95 - $2.11(\mathrm{~m}, 1 \mathrm{H}) 1.99-2.06(\mathrm{~m}, 1 \mathrm{H}) 2.28$ - $2.41(\mathrm{~m}, 1 \mathrm{H}) 2.59$ - $2.69(\mathrm{~m}, 1 \mathrm{H}) 2.87$ - 2.97 (m, 1 H) 2.97 - $3.09(\mathrm{~m}, 3 \mathrm{H}) 2.97$ - $3.06(\mathrm{~m}, 1 \mathrm{H}) 3.37$ - $3.46(\mathrm{~m}, 1 \mathrm{H}) 3.51$ - 3.59 (m, 1 H) 3.98 (quin, $J=7.27 \mathrm{~Hz}, 1 \mathrm{H}) 6.15(\mathrm{br} \mathrm{s}, 1 \mathrm{H}) 7.28-7.35(\mathrm{~m}, 2 \mathrm{H}) 7.35-7.42(\mathrm{~m}, 2 \mathrm{H}) 7.80$ (dd, $J=8.31,2.81 \mathrm{~Hz}, 1 \mathrm{H}) 8.03$ (br d, $J=8.19 \mathrm{~Hz}, 1 \mathrm{H}) 8.09$ (d, J=8.31 Hz, $1 \mathrm{H}$ ). 


\section{${ }^{13}$ C NMR for compound 8e}

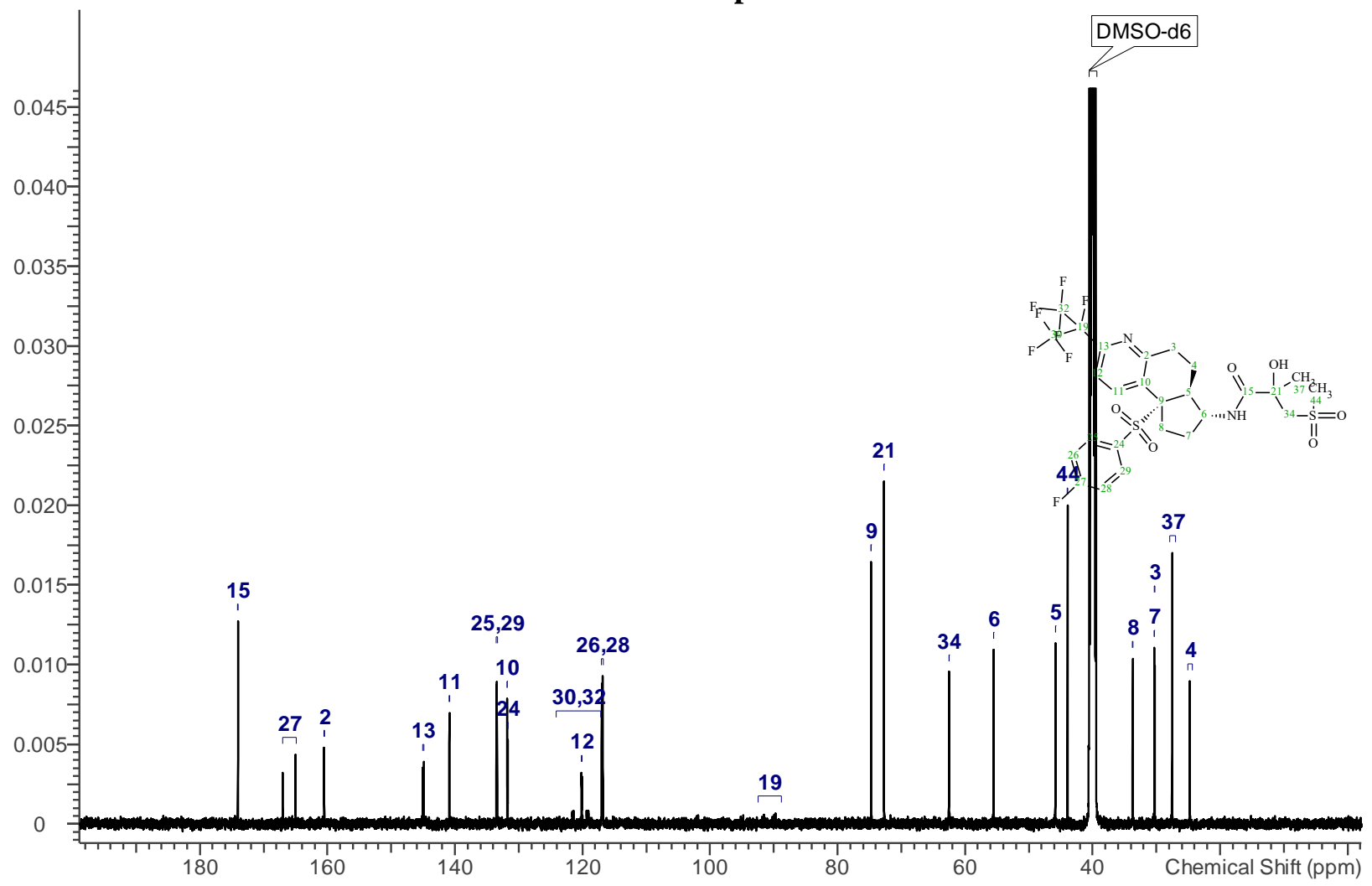

${ }^{13} \mathrm{C}$ NMR (126 MHz, DMSO-d $d_{6} \delta$ ppm 24.76 (s, 1 C) 27.52 (s, 1 C) 30.27 (br s, 1 C) 30.31 (s, 1 C) $33.70(\mathrm{~s}, 1 \mathrm{C}) 43.92(\mathrm{~s}, 1 \mathrm{C}) 45.82(\mathrm{~s}, 1 \mathrm{C}) 55.51(\mathrm{~s}, 1 \mathrm{C}) 62.50(\mathrm{~s}, 1 \mathrm{C}) 72.70(\mathrm{~s}, 1 \mathrm{C}) 74.73$ (s, 1 C) 88.78 - $92.41(\mathrm{~m}, 1 \mathrm{C}) 116.89$ (d, J=22.71 Hz, 2 C) 117.10 - 124.11 (m, 2 C) 120.09 (d, $J=8.17 \mathrm{~Hz}, 1 \mathrm{C}) 131.72(\mathrm{~d}, J=2.72 \mathrm{~Hz}, 1 \mathrm{C}) 131.78(\mathrm{~s}, 1 \mathrm{C}) 133.43$ (d, J=9.99 Hz, 2 C) 140.86 (s, $1 \mathrm{C}) 144.95$ (d, $J=25.43 \mathrm{~Hz}, 1 \mathrm{C}) 160.52$ (d, $J=2.72 \mathrm{~Hz}, 1 \mathrm{C}) 165.97$ (d, J=255.22 Hz, $1 \mathrm{C}$ ) 174.03 (s, $1 \mathrm{C})$. 
Crystallographic parameters for the co-crystal structure of 8e with the LBD of ROR $\gamma \mathrm{t}$ (PDB ID: 7LUK).

Crystallographic data collection and processing: Values for the outer shell are given in parentheses.

Date of Data Collection

Diffraction source

Wavelength $(\AA)$

Temperature $(\mathrm{K})$

Detector

Crystal-detector distance ( $\mathrm{mm}$ )

Rotation range per image $\left(^{\circ}\right)$

Total rotation range $\left(^{\circ}\right)$

Exposure time per image (s)

Space group

$a, b, c(\AA)$

$\alpha, \beta, \gamma\left(^{\circ}\right)$

Resolution range $(\AA)$

Total No. of reflections

No. of unique reflections

Completeness (\%)

$\langle I / \sigma(I)\rangle$

Rmerge
2018-06-20

APS beamline 17-ID

1.000

100

Dectris pilatus $6 M$ pixel

275

0.25

180

0.077

$P 41212$

$62.22,62.22,156.58$

$90,90,90$

57.82-2.09 (2.27-2.09)

$174878(7,901)$

14027 (701)

$73.4(17.0)$

$10.0(1.5)$

0.228 (1.944)

Overall $B$ factor from Wilson plot $\left(\AA^{2}\right) \quad 35.69$

Crystallographic structure refinement: Values for the outer shell are given in parentheses.

Resolution range $(\AA)$

Completeness (\%)

No. of reflections, working set

No. of reflections, test set

Final $R$ cryst

Final $R$ free

Cruickshank DPI

No. of non-H atoms

Protein

Ligand

Water

Total

R.m.s. deviations

Bonds $(\AA)$

Angles ( ${ }^{\circ}$ )

Average $B$ factors $\left(\AA^{2}\right)$
57.82-2.087 (2.22-2.09)

73.5

14027 (379)

718

$0.206(0.209)$

$0.234(0.260)$

0.302

2037

44

72

2153

0.008

0.86 


\section{REFERENCES}

(1) Marcoux, D.; Duan, J. J.-W.; Shi, Q.; Cherney, R. J.; Srivastava, A. S.; Cornelius, L.; Batt, D. G.; Liu, Q.; Beaudoin-Bertrand, M.; Weigelt, C. A.; Khandelwal, P.; Vishwakrishnan, S.; Selvakumar, K.; Karmakar, A.; Gupta, A. K.; Basha, M.; Ramlingam, S.; Manjunath, N.; Vanteru, S.; Karmakar, S.; Maddala, N.; Vetrichelvan, M.; Gupta, A.; Rampulla, R. A.; Mathur, A.; Yip, S.; Li, P.; Wu, D.-R.; Khan, J.; Ruzanov, M.; Sack, J. S.; Wang, J.; Yarde, M.; Cvijic, M. E.; Li, S.; Shuster, D. J.; Borowski, V.; Xie, J. H.; McIntyre, K. W.;

Obermeier, M. T.; Fura, A.; Stefanski, K.; Cornelius, G.; Hynes, J.; Tino, J. A.; Macor, J. E.; Salter-Cid, L.; Denton, R.; Zhao, Q.; Carter, P. H.; Dhar, T. G. M. Rationally designed, conformationally constrained inverse agonists of ROR $\gamma \mathrm{t}$ - identification of a potent, selective series with biologic-like in vivo efficacy. J. Med. Chem. 2019, 62, 9931.

(2) Liu, Q.; Batt, D. G.; Weigelt, C. A.; Yip, S.; Wu, D.-R.; Ruzanov, M.; Sack, J. S.; Wang, J.; Yarde, M.; Li, S.; Shuster, D. J.; Xie, J. H.; Sherry, T.; Obermeier, M. T.; Fura, A.; Stefanski, K.; Cornelius, G.; Khandelwal, P.; Tino, J. A.; Macor, J. E.; Salter-Cid, L.; Denton, R.; Zhao, Q.; Dhar, T. G. M. Novel tricyclic pyroglutamide derivatives as potent ROR $\gamma t$ inverse agonists identified using a virtual screening approach. ACS Med. Chem. Lett. 2020, 11, 2510.

(3) Yang, M. G.; Beaudoin Bertrand, M.; Xiao, Z.; Marcoux, D.; Weigelt, C. A.; Yip, S.; Wu, D.-R.; Ruzanov, M.; Sack, J. S.; Wang, J.; Yarde, M.; Li, S.; Shuster, D. J.; Xie, J. H.; Sherry, T.; Obermeier, M. T.; Fura, A.; Stefanski, K.; Cornelius, G.; Khandelwal, P.; Karmakar, A.; Basha, M.; Babu, V.; Gupta, A. K.; Mathur, A.; Salter-Cid, L.; Denton, R.; Zhao, Q.; Dhar, T. G. M. Tricyclic-carbocyclic ROR $\gamma$ t inverse agonists - discovery of BMS-986313. J. Med. Chem. 2021, 64, 2714. 